\title{
Failure Pressure Prediction of High Toughness Pipeline with a Single Corrosion Defect Subjected to Combined Loadings Using Artificial Neural Network (ANN)
}

\author{
Suria Devi Vijaya Kumar*(D), Saravanan Karuppanan and Mark Ovinis (D)
}

check for

updates

Citation: Vijaya Kumar, S.D.; Karuppanan, S.; Ovinis, M. Failure Pressure Prediction of High Toughness Pipeline with a Single Corrosion Defect Subjected to Combined Loadings Using Artificial Neural Network (ANN). Metals 2021, 11, 373. https://doi.org/10.3390/ met11020373

Academic Editor: Xing-Qiu Chen

Received: 22 December 2020

Accepted: 5 February 2021

Published: 23 February 2021

Publisher's Note: MDPI stays neutral with regard to jurisdictional claims in published maps and institutional affiliations.

Copyright: (c) 2021 by the authors. Licensee MDPI, Basel, Switzerland. This article is an open access article distributed under the terms and conditions of the Creative Commons Attribution (CC BY) license (https:// creativecommons.org/licenses/by/ $4.0 /)$.
Mechanical Engineering Department, Universiti Teknologi PETRONAS, Bandar Seri Iskandar 32610, Perak Darul Ridzuan, Malaysia; saravanan_karuppanan@utp.edu.my (S.K.); mark_ovinis@utp.edu.my (M.O.)

* Correspondence: suria_19001431@utp.edu.my

\begin{abstract}
Conventional pipeline corrosion assessment methods result in failure pressure predictions that are conservative, especially for pipelines that are subjected to internal pressure and axial compressive stress. Alternatively, numerical methods may be used. However, they are computationally expensive. This paper proposes an analytical equation based on finite element analysis (FEA) for the failure pressure prediction of a high toughness corroded pipeline with a single corrosion defect subjected to internal pressure and axial compressive stress. The equation was developed based on the weights and biases of an Artificial Neural Network (ANN) model trained with failure pressure from finite element analysis (FEA) of a high toughness pipeline for various defect depths, defect lengths, and axial compressive stresses. The proposed model was validated against actual burst test results for high toughness materials and was found to be capable of making accurate predictions with a coefficient of determination $\left(R^{2}\right)$ of 0.99 . An extensive parametric study using the proposed model was subsequently conducted to determine the effects of defect length, defect depth, and axial compressive stress on the failure pressure of a corroded pipe with a single defect. The application of ANN together with FEA has shown promising results in the development of an empirical solution for the failure pressure prediction of pipes with a single corrosion defect subjected to internal pressure and axial compressive stress.
\end{abstract}

Keywords: artificial neural network; finite element analysis; pipeline corrosion assessment method

\section{Introduction}

\subsection{Pipeline Corrosion}

In the oil and gas industry, pipelines play a critical role in transporting hydrocarbons from one location to another. Often, these pipelines are subjected to harsh conditions such as corrosive environments, causing them to be prone to corrosion [1]. The integrity of a pipeline is compromised when there is a corrosion defect. Due to the uneven degradation of the pipe wall, the distribution of hoop stress across the pipeline is nonuniform [2-4]. When this occurs, the pipeline will fail at a pressure lower than the design pressure.

During operations, as fluid flows through a pipeline, pressure is exerted on the pipeline wall, causing circumferential expansion of the pipeline and strain buildup at the region of the defect [5]. The largest stress is experienced at the deepest point of the defect region, leading to premature pipe failure when the stress exceeds the true ultimate tensile strength of the pipe. Hence it is crucial that the integrity of the pipeline is assessed from time to time, to prevent disastrous failures.

\subsection{Pipeline Integrity Assessment Methods}

Corrosion defects form in various shapes and sizes in a non-uniform manner. Pipelines of various grades have different tensile properties and therefore differ in their behaviour 
when subjected to stresses in the presence of corrosion defects. A general corrosion assessment method that can be used for all types of corrosion defects and pipeline grades needs to account for the defect dimensions and configurations, stresses acting on it, and the material properties of the different pipe grades. Due to this complexity, various assumptions have to be made to simplify the assessment process [6-10]. As such, the failure pressure prediction of a pipe for each corrosion assessment method differs due to the simplifications that were made during their development, as summarised in Table 1 [11].

Table 1. Comparison of pipe failure pressure assessment methods.

\begin{tabular}{|c|c|c|c|}
\hline Method & Fundamental Equation & Governing Assumption & Material Restriction \\
\hline ASME B31G & NG-18 & \multirow{4}{*}{$\begin{array}{l}\text { Tensile property of a pipe } \\
\text { determines the mechanism that } \\
\text { causes pipe failure. }\end{array}$} & Low toughness \\
\hline Modified B31G & NG-18 & & Low toughness \\
\hline SHELL 92 & NG-18 & & - \\
\hline A Modified Criterion for & & & \\
\hline $\begin{array}{l}\text { Evaluating the Remaining } \\
\text { Strength of Corroded Pipe } \\
\text { (RSTRENG) }\end{array}$ & NG-18 & & - \\
\hline DNV RP-F101 & NG-18 & \multirow{2}{*}{$\begin{array}{l}\text { Pipe failure due to plastic collapse } \\
\text { (plastic flow), where the ultimate } \\
\text { tensile strength is the flow stress. }\end{array}$} & Moderate toughness \\
\hline $\begin{array}{c}\text { Pipe Corrosion Criterion } \\
\text { (PCORRC) }\end{array}$ & Numerical studies & & Moderate to high toughness \\
\hline
\end{tabular}

Failure pressure predictions based on conventional corrosion assessment codes are conservative, leading to unwarranted repairs and premature replacement of pipeline, contributing to unnecessary costs [12]. Of all the codes that are being used in the industry for failure pressure prediction of corrosion defects subjected to internal pressure and axial compressive stress, the DNV-RP-F101 corrosion assessment code (DNV) is the most comprehensive [11].

\subsection{DNV for Pipeline Failure Pressure Prediction}

Pipelines are subjected to both internal pressure and axial compressive stress. Fluid flow in a pipeline contributes to the internal pressure exerted on the pipeline walls, which causes the pipe to expand in the circumferential direction, resulting in the contraction of the pipe in the longitudinal direction due to Poisson's effect [13-15]. This phenomenon causes the pipeline to experience axial compressive stress. Studies have shown that the increase in depth and length of a corrosion defect significantly influences the failure pressure of the pipeline in the presence of axial compressive stress [16-18].

The DNV code is capable of predicting the failure pressure of a pipe with a single corrosion defect subjected to both internal pressure and axial compressive stress [7]. The main equation in DNV RP-F101 for failure pressure prediction of a pipe with a single corrosion defect subjected to internal pressure is given by Equation (1).

$$
p_{c o r r}=\gamma_{m}\left(\frac{2 t \sigma_{U T S}}{D-t}\right)\left(\frac{1-\gamma_{d}\left[(d / t)_{\text {meas }}+\varepsilon_{d} S t D(d / t)\right]}{1-\frac{\gamma_{d}\left[(d / t)_{\text {meas }}+\varepsilon_{d} S t D(d / t)\right]}{\sqrt{1+0.31(l / \sqrt{D t})^{2}}}}\right)
$$

To account for axial compressive stress, a correction factor, $H_{1}$, determined using Equation (2), is required.

$$
H_{1}=\frac{1+\left(\frac{\sigma_{L}}{\xi \sigma_{\text {UTS }}}\right)\left(\frac{1}{1-(d / t) \theta}\right)}{1-\left(\frac{\gamma_{m}}{2 \xi[1-(d / t) \theta]}\right)\left(\frac{1-\gamma_{d}\left[(d / t)_{\text {meas }}+\varepsilon_{d} S t D(d / t)\right]}{1-\frac{\gamma_{d}\left[(d / t)_{\text {meas }}+\varepsilon_{d} S t D(d / t)\right]}{\sqrt{1+0.31(l / \sqrt{D t})^{2}}}}\right)}
$$


The failure pressure prediction of a pipe with a single corrosion defect subjected to internal pressure and axial compressive stress is given by Equation (3).

$$
P_{f, D N V}=\gamma_{m}\left(\frac{2 t \sigma_{U T S}}{D-t}\right)\left(\frac{1-\gamma_{d}\left[(d / t)_{\text {meas }}+\varepsilon_{d} S t D(d / t)\right]}{1-\frac{\gamma_{d}\left[(d / t)_{\text {meas }}+\varepsilon_{d} S t D(d / t)\right]}{\sqrt{1+0.31(l / \sqrt{D t})^{2}}}}\right) H_{1}
$$

Despite the comprehensiveness of the DNV code, it is recommended to be used to assess pipeline materials of medium toughness only and is therefore inaccurate for pipelines with high toughness. In addition, its predictions are conservative, as it uses the ultimate tensile strength, $\sigma_{U T S}$, rather than the true ultimate tensile strength, $\sigma^{*}$ UTS, of the material, which represents the actual fracture point of a material [11]. In addition, the assumptions and simplifications made related to the corrosion defect dimensions, pipe material properties, and axial compressive stress acting on the pipe add to the conservatism of the method.

\subsection{Finite Element Method (FEM) for Pipeline Failure Pressure Prediction}

Due to the conservativeness of the current corrosion assessment codes, Finite Element Method (FEM) is widely applied and is categorized as a Level 3 assessment method for evaluating the failure pressure of pipelines [6]. Being the most advanced assessment level, numerical methods are used in Level 3 evaluation and considers more information for the prediction of failure pressure compared to Levels 0,1 , and 2. FEM allows nonlinear structural analysis in with respect to geometric and material nonlinearity, by considering the uniaxial true stress-strain curve of the material, which is crucial for structures that change in geometry due to large displacements. As the pipe deforms, the equilibrium equations take into consideration the geometrical changes of the pipe as well as the nonlinear stress-strain relationship of the material. This enables accurate predictions of failure pressures, as it accounts for strain hardening, plastic and elastic deformation of the material [4].

However, FEM must be validated with the actual burst test result. This is because FEM is usually simplified for ease of simulation, with the accuracy of the results dependent on the proper choice of boundary conditions, model features and material properties [19]. Furthermore, FEM needs to be optimized in terms of meshing, to ensure that the model is able to run simulations efficiently with respect to time, without compromising on the accuracy of the results [11].

\subsection{Artificial Neural Network (ANN) as a Pipeline Failure prEssure Assessment Method}

To reduce the computation time of a finite element analysis (FEA), quarter models are utilised and symmetric boundary conditions are applied to ensure that the model is treated as a whole pipe. Despite imposing symmetric boundary conditions, the incorporation of axial compressive stress into FEM will greatly increase the complexity and computing time of the model, which can take up to three hours per simulation. As such it is not practical to use FEM to predict the failure pressure of multiple corroded pipelines subjected to internal pressure and axial compressive stress. As an alternative, an artificial neural network based on FEA can be trained and used instead, as it can provide results within seconds.

In a pipe, changes in the defect length, defect depth and axial compressive stress cause a change in the failure pressure of the pipe in a nonlinear manner. In various studies that have been carried out to improve assessment methods of corroded pipes, ANN has proven to be very useful, as it has the ability to learn from nonlinear data and return accurate failure pressure predictions [20]. ANN mimics the synapses in a human brain by employing weights and biases to the neurons in the hidden layers of the neural network [21]. The input and output data are analysed by a neural network and appropriate weights and biases are allocated to each neuron until the neural network produces accurate results. When this is achieved, the neural network is said to be trained. It is crucial that the training 
dataset consists of a sufficient number of inputs and corresponding outputs to minimize percentage error in the output of the neural network.

Parametric studies using FEM can be used to generate a set of training data to be used for the development of the ANN. When the model has been sufficiently trained, the ANN can be used to predict the failure pressure of a corroded pipeline if it falls within the prediction range of the model. Xu et al. [22] utilised this approach to predict the failure pressure of the corroded pipeline with interacting defects subjected to internal pressure only. The failure pressure predictions using ANN were comparable with the experimental burst pressure. In addition, the failure pressure prediction using ANN had a strong correlation with the failure pressures obtained from the ASME-B31G and DNV's corrosion assessment codes.

In this paper, an empirical equation to predict the failure pressure of pipelines with a single corrosion defect subjected to internal pressure and axial compressive stress was formulated based on the weights and biases from an ANN trained with values from parametric studies utilizing FEA. The equation was then validated against arbitrary finite element (FE) models with single defect corrosion, and actual full-scale burst tests from past research.

\section{Methodology}

\subsection{Overview of Geometric Parameters}

In this study, the parameters taken into consideration to calculate the failure pressure of a pipe with single corrosion defect were the length of the defect, depth of the defect, and axial compressive stress acting on the pipe. These parameters are presented as normalised values. The pipe geometry and the normalised values of the parameters are listed in Table 2. The corrosion defect width was not included in this study, as its influence on the failure pressure of a corroded pipeline subjected to internal pressure and axial compressive stress is minimal $[6,7,11]$. Based on the parameters listed in Table 2, the failure pressures were obtained using two methods, FEM and DNV. The failure pressures obtained using FEM was used to generate training data for the ANN, while the failure pressures obtained using the DNV method was used to compare both the methods in terms of accuracy.

Table 2. Geometric parameters for finite element analysis (FEA) parametric study.

\begin{tabular}{cc}
\hline Input Parameters & Value (s) \\
\hline Outer diameter of pipe, $D(\mathrm{~mm})$ & 300 \\
Wall thickness, $t(\mathrm{~mm})$ & 10 \\
Straight pipe length, $L(\mathrm{~mm})$ & 2000 \\
Defect width, $w(\mathrm{~mm})$ & 100 \\
Normalized defect length, $l / D$ & $0.0,0.2,0.4,0.6,0.8$ \\
Normalized defect depth, $d / t$ & $0.0,0.2,0.4,0.6,0.8$ \\
Normalized axial compressive stress, $\sigma_{c} / \sigma_{y}$ & $0.0,0.2,0.4,0.6,0.8$ \\
\hline
\end{tabular}

The calibrated safety factor approach (Part A) from the DNV-RP-F101 corroded pipeline assessment manual was used for the calculation of the failure pressure of pipes with a single defect subjected to internal pressure and axial compressive stress. In this approach, the size of the defect depth and material properties must be specified in detail [7]. The DNV corrosion assessment factors that were applied and their respective assumptions are summarized in Table 3. 
Table 3. DNV corrosion assessment factors and assumptions.

\begin{tabular}{|c|c|c|}
\hline Factor & Value & Assumptions \\
\hline Model prediction partial safety factor, $\gamma_{m}$ & 1.00 & Perfect pipe inspection method. \\
\hline Corrosion depth partial safety factor, $\gamma_{d}$ & 1.00 & Exact corrosion defect depth. \\
\hline Fractile value, $\varepsilon_{d}$ & 0.00 & $\begin{array}{c}\text { Low tolerance and high confidence level corrosion inspection } \\
\text { method. }\end{array}$ \\
\hline Usage factor, $\xi$ & 1.00 & Pristine pipe. \\
\hline Relative depth accuracy, acc_rel & 0.00 & High corrosion depth inspection accuracy with zero tolerance. \\
\hline Confidence level, conf & 0.99 & $99 \%$ confidence level on corrosion defect dimensions. \\
\hline
\end{tabular}

\subsection{Development of the Finite Element Method}

The development of the FEM could be divided into 4 steps, modelling of the pipe with single corrosion defect, meshing of the pipe model, application of boundary conditions, as well as loadings, and determination of failure criterion, as summarized in Figure 1.

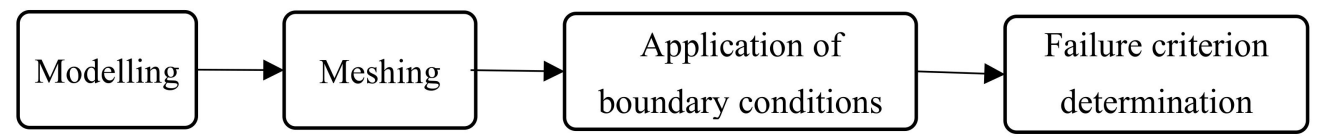

Figure 1. Flow of the development of the FEM.

\subsubsection{Modelling of Pipe with Single Corrosion Defect}

Since axial compressive stress will be imposed, the pipes were modelled with endplates of $20 \mathrm{~mm}$ to ensure an even distribution of stress across the pipe wall. The full length of the modelled pipe was set to $2000 \mathrm{~mm}$, to prevent end cap effects, while the pipe external diameter and wall thickness were set to be $300 \mathrm{~mm}$ and $10 \mathrm{~mm}$, respectively. In this study, a quarter of the corroded pipe, as illustrated in Figure 2, was modelled, and used in the FE simulations to reduce computational time, without compromising the accuracy of the results. As for the defect idealization, a rectangular-shaped corrosion defect was modelled. This idealization was also utilised in the DNV method, as it allows for a safer lower bound failure pressure prediction, without compromising much on the accuracy of the failure pressure prediction $[7,23-25]$.
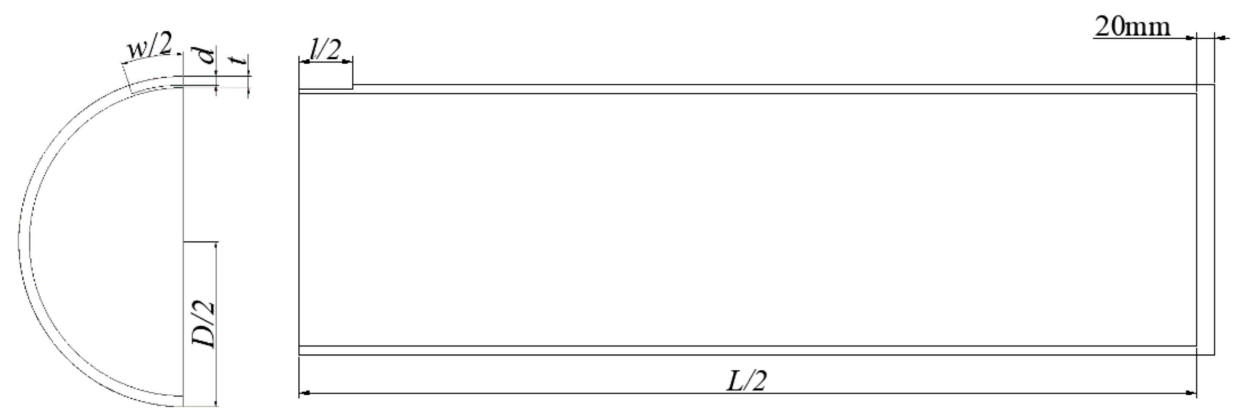

Figure 2. An annotated quarter pipe model used for FEA.

\subsubsection{Meshing of the Pipe Model}

ANSYS 16.1 (Ansys Inc., Canonsburg, PA, USA) Structural Product of Mechanical ANSYS Parametric Design Language (APDL) or ANSYS for short, was used for the meshing and FEA of the corroded pipe models. ANSYS offers a wide range of element types for meshing depending on the material geometry and properties. In this study, due to the thickness of the pressurized pipe walls, solid elements were used instead of shell elements to increase the accuracy of the element meshing [26]. The pipe body and defect region were meshed using hexahedral SOLID185 elements while the endplates were meshed using tetrahedral SOLID186 elements. SOLID185 is defined by 8 nodes having three degrees of freedom while SOLID186 can tolerate irregular shapes such as curved boundaries. 
Both these elements accommodate high-stress stiffening, creep, large deflection, plasticity, swelling, and large strain [27]. The application of SOLID185 and SOLID186 elements on a pipe model is illustrated in Figures 3 and 4 respectively.

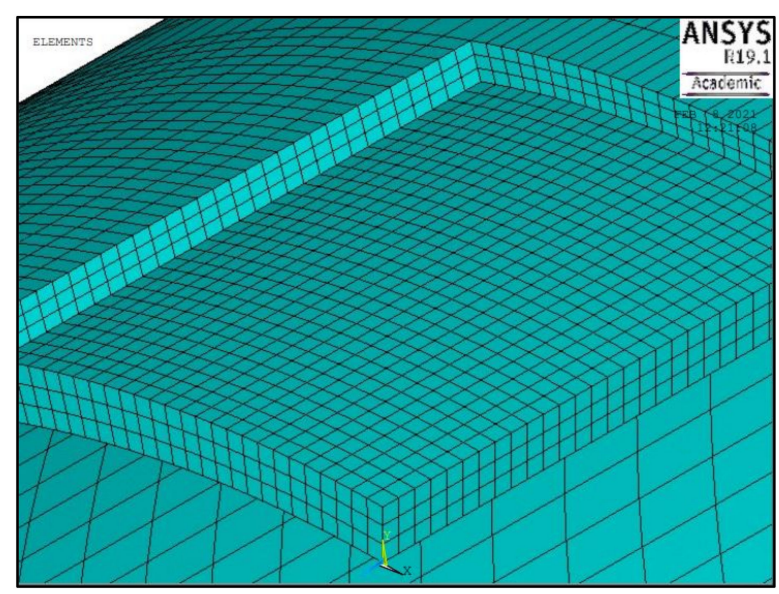

Figure 3. Hexahedral SOLID185 elements used to mesh the pipe body and defect region.

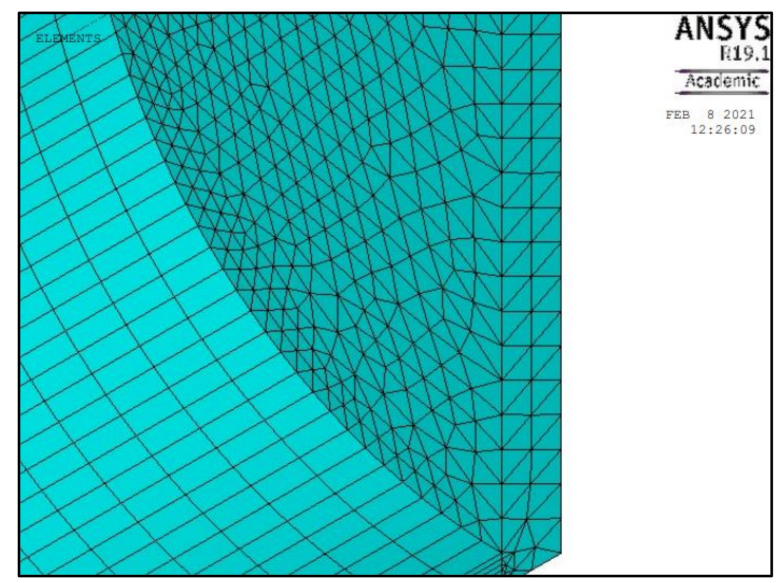

Figure 4. Tetrahedral SOLID186 elements used to mesh the endplate.

The number of mesh layers was set to 3, in accordance with the British Standards Institution [28]. The length and width of the mesh were both set to $2 \mathrm{~mm}$. An aspect ratio of 0.5 was applied to the elements moving away from the defect region, with a total of 80 divisions. A convergence test was conducted to determine these element settings, to ensure minimal computation time without compromising on the accuracy of the FEM.

\subsubsection{Application of Boundary Conditions and Loadings}

To ensure that the quarter pipe model was treated as a whole model, symmetric boundary conditions were applied to the model during the FEM using ANSYS. To prevent undesired rigid body movements, degree of freedom (DOF) constraints in the $\mathrm{x}, \mathrm{y}$, and $z$ directions were applied at $4 / 5$ of the quarter model length away from the corrosion defect region (Figure 5). Incremental ramped loading of the internal pressure and axial compressive stress from the first time step was applied on the inner surface of the pipe and endplate respectively, as illustrated in Figure 5. 


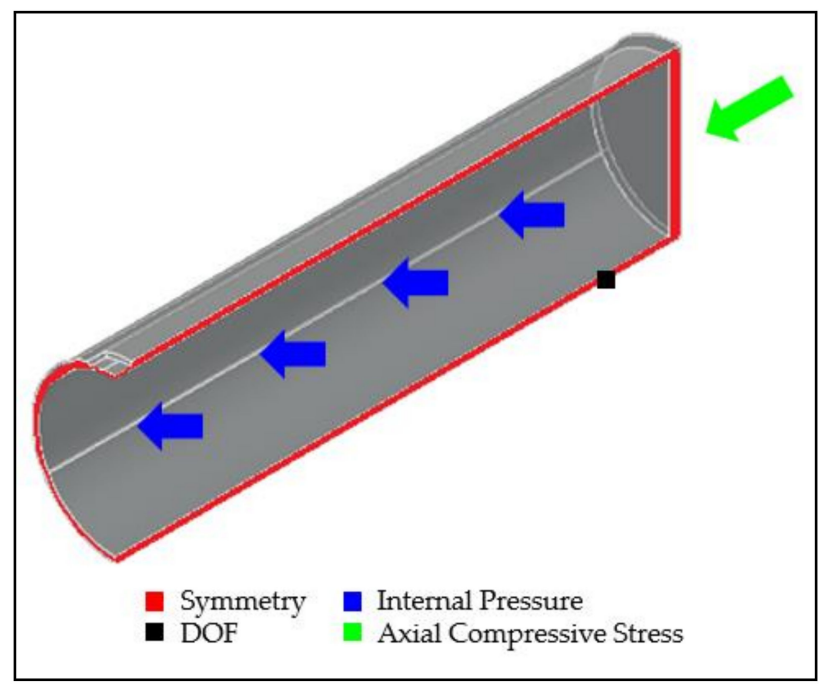

Figure 5. Application of symmetrical boundary conditions, internal pressure, compressive stress, and degree of freedom (DOF) constraint for quarter pipe models.

\subsubsection{Failure Criterion}

In this study, a stress-based criterion was utilised to determine the point of pipe failure. When the equivalent stress exceeds the true ultimate tensile stress of the material, plastic collapse occurs. During FEA, the failure pressure of a pipe was determined by observing the von Mises stress distribution across the pipe, where the region of defect is the most critical part of the pipe. When the von Mises stress reaches the true ultimate tensile strength of the material, the material is said to have failed, as illustrated in Figure 6 [29].

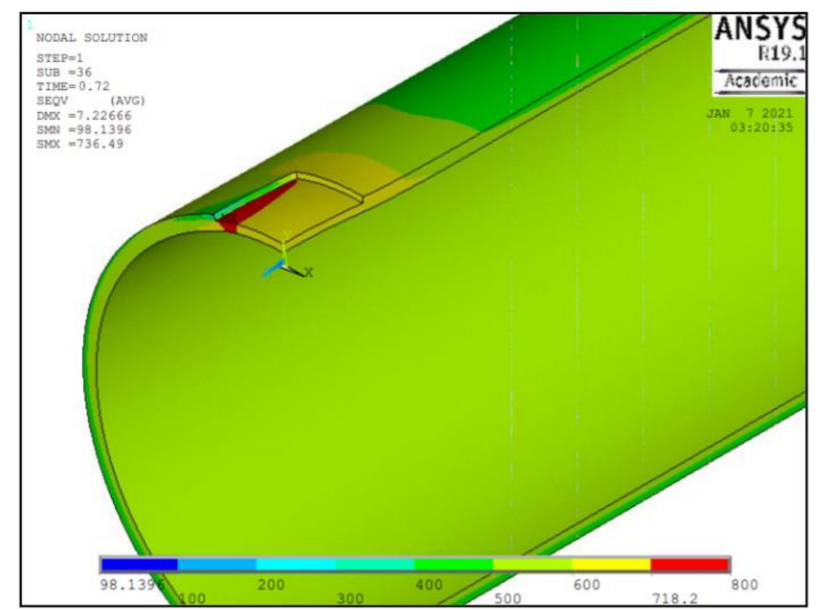

Figure 6. Red contour depicting the region of failure of the pipe.

In ANSYS, the stress distribution along the corroded pipe was analyzed using von Mises theory, where the effective stress was calculated as a function of hoop, radial, and axial stress, as shown in Equation (4) [2]. When the effective stress reached the true ultimate tensile strength of the material, the time step of the simulation was recorded, and the corresponding pressure was calculated and recorded as the failure pressure of the pipe.

$$
\sigma_{e}=\sqrt{\frac{1}{2}\left[\left(\sigma_{h}-\sigma_{r}\right)^{2}+\left(\sigma_{h}-\sigma_{l}\right)^{2}+\left(\sigma_{r}-\sigma_{l}\right)^{2}\right]}
$$

\subsection{Development of the Finite Element Method}

The development of the ANN could be divided into 3 steps, the determination of the ANN architecture, training, and validation of the ANN model, as summarized in Figure 7. 


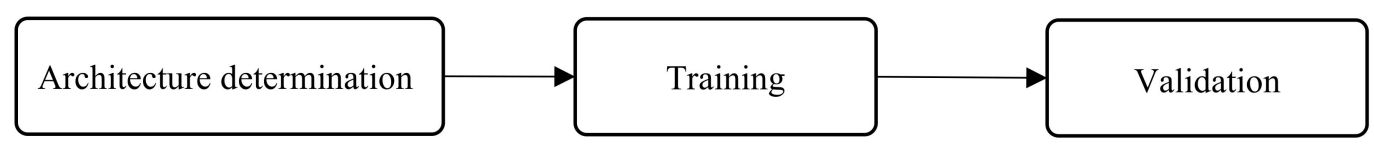

Figure 7. Flow of the development of the ANN.

\subsubsection{Determination of the ANN Architecture}

In this study, MathWorks MATLAB R2019b was utilised to develop a feed-forward neural network. This architecture was utilised as it models the relationship between the input and output based on a set of training data. The ANN was designed to receive three input values and output one value. The input values were the normalised defect depth, defect length and axial compressive stress, while the output value was the normalised pipe failure pressure. The ANN was developed with two hidden layers, where the first and second layer consisted of three and two neurons respectively, as illustrated in Figure 8, which was extracted from MathWorks MATLAB R2019b. The number of hidden layers and neurons in each hidden layer was determined based on regression analysis of the ANN model.

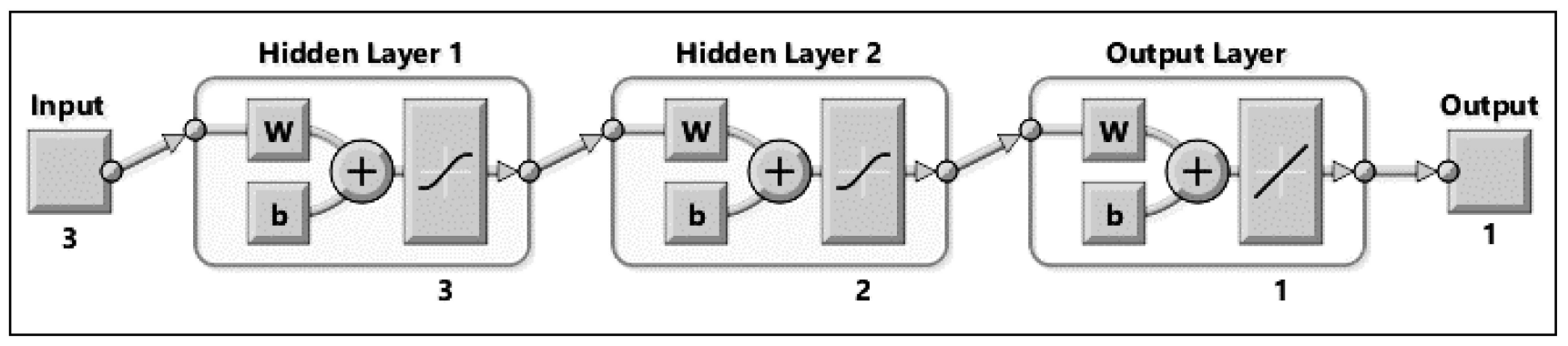

Figure 8. Overview of the Artificial Neural Network (ANN) model.

\subsubsection{Training of the ANN Model}

The ANN model was developed utilising the Levenberg-Marquardt back-propagation algorithm. This training function was used to optimise the weight and biases of the ANN model, as it requires less computation time and is recommended for supervised learning algorithms. A hyperbolic tangent function, as shown in Equation (5), was used as the activation function for neurons at the hidden layers; and a linear function, as shown in Equation (6), was used as the activation function at the output node. The training data for the ANN were obtained from the FEA.

$$
\begin{gathered}
a(x)=\frac{2}{\left(1+e^{-2 x}\right)-1} \\
f(x)=x
\end{gathered}
$$

\subsubsection{Validation of the ANN Model}

The ability of the ANN to produce outcomes close to the training data was measured using the coefficient of determination $\left(R^{2}\right)$ of the model. The $R^{2}$ value ranged from 0.0 to 1.0, with a greater $R^{2}$ value indicating a better goodness of fit, which is the distance between the fitted line of the ANN's regression plot and the training data points.

\subsection{Material Properties}

A high toughness pipe grade of API 5L X80 was utilised in this study. The material properties of the pipe body were represented by a nonlinear true stress-strain curve of the material, as illustrated in Figure 9. 


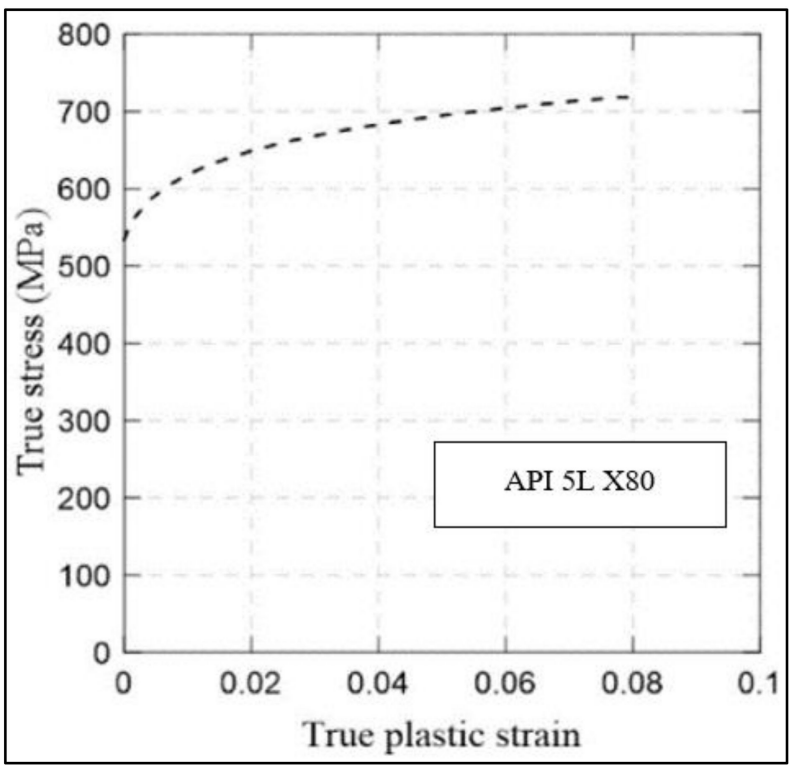

Figure 9. True stress-strain curve for API 5L X80 steel, data from [19].

The true ultimate tensile strength and yield strength values were 718.2 $\mathrm{MPa}$ and $531 \mathrm{MPa}$, respectively, with a true plastic strain value of 0.079 . The Poisson's ratio and modulus of elasticity of the pipe were set at 0.3 and 200 GPa respectively, and 0.3 and 200 TPa respectively for the endplate. The endplate was assumed to be of a rigid body and does not undergo deformation despite large load application. During the FEA, material stress stiffening, large strain and displacements were considered, to account for high material nonlinearity in the pipe body.

\section{Validation of the Finite Element Method}

The FEM was validated against full-scale burst test results to ensure the reliability and accuracy of the FEM. Table 4 summarises the validation of the FEM against actual full-scale burst test. Tests 5 and 6 by Bjornoy and Sigurdson (2000) include combined internal pressure and axial compressive stress loading. The other test models were subjected to internal pressure loading only. The maximum percentage difference between the failure pressure obtained using FEM and actual full-scale burst tests for pipes subjected to internal pressure only was $1.08 \%$. As for pipes subjected to internal pressure and axial compressive stress, the maximum percentage difference obtained was 5.92\%. As the percentage differences are below $10 \%$, it is evident that FEM can be used as a failure pressure data generation tool for the training of the ANN.

Table 4. Summary of FEA failure pressure validation against full-scale burst tests for pipes subjected to internal pressure only, and internal pressure and axial compressive stress, data from [30-32].

\begin{tabular}{cccccc}
\hline Author(s), Year & \multicolumn{3}{c}{ Bjornoy \& Sigurdsson, 2000 } & B. Ma et al., 2013 & Benjamin et al., 2005 \\
\hline Grade & X52 & X52 & X52 & X65 & X80 \\
Specimen & Test 1 & Test 5 & Test 6 & Test 61 & IDTS 2 \\
$d(\mathrm{~mm})$ & 5.15 & 3.09 & 3.09 & 4.40 & 5.39 \\
$l(\mathrm{~mm})$ & 243 & 162 & 162 & 200 & 39.6 \\
$w(\mathrm{~mm})$ & 154.5 & 30.9 & 30.9 & 50.0 & 31.9 \\
$\sigma_{l}(\mathrm{MPa})$ & 0.0 & 48.0 & 84.0 & 0.0 & 22.0 \\
Burst Pressure (MPa) & 23.20 & 28.60 & 28.70 & 24.11 & 22.40 \\
FEA failure pressure (MPa) & 22.95 & 28.35 & 27.00 & 23.25 & 1.23 \\
Percentage Difference (\%) & 1.08 & 0.87 & 5.92 & 3.57 & \\
\hline
\end{tabular}




\section{Results and Discussion}

\subsection{Comparison of Pipe Failure Pressure Prediction Using FEA and DNV Method}

During the development of the DNV method for the assessment of pipes with a single corrosion defect subjected to internal pressure and axial compressive stress, full-scale burst tests were conducted on pipes from grade API 5L X45 to API 5L X65 for the validation of the assessment method. As such, this code is recommended to be used to predict the failure pressure of pipelines within that range of pipe grades. Furthermore, the validation tests for the assessment of the method are mostly done using pipes subjected to internal pressure loading only. Only $7.25 \%$ of the validation tests included axial compressive stress being imposed on the pipe. Hence, the validation in DNV for assessing the failure pressure of pipes with a single corrosion defect subjected to internal pressure and axial compressive stress is less comprehensive than the assessment procedure used to predict the failure pressure of a pipe with single corrosion defect subjected to internal pressure only.

Based on Figure 10, for API 5L X80 pipes with a single corrosion defect subjected to internal pressure only, it was observed that for defect depths of 0.2 and 0.4 , the conservativeness of the DNV method is more significant, with a percentage difference ranging from $-7.72 \%$ to -13.11 . As the defect depth is increased to 0.6 and 0.8 , the conservativeness of the DNV method reduces, with a percentage difference ranging from $-4.33 \%$ to $-10.00 \%$.

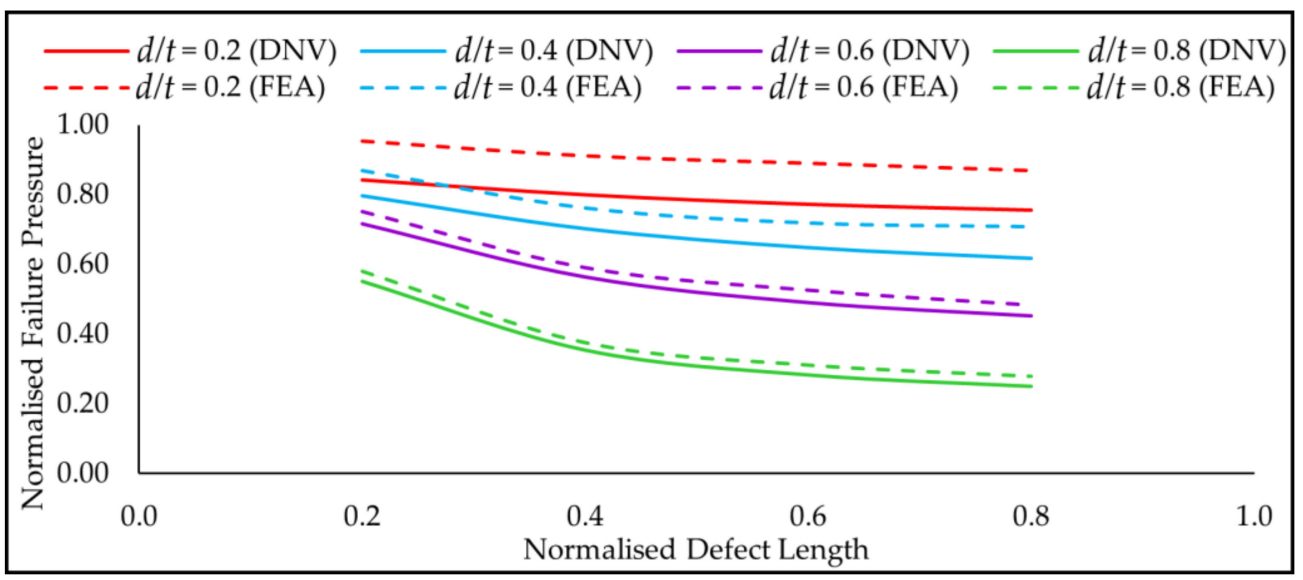

Figure 10. Normalized failure pressure predictions of FEA and DNV for API 5L X80 pipe subjected to internal pressure only.

However, when axial compressive stress was introduced, the DNV codes perform very poorly, especially for normalised axial compressive stress of 0.4 and above with percentage differences ranging from $-0.19 \%$ to $-65.95 \%$, as depicted in Figure 11 . Based on Figure 11 , the normalised failure pressure obtained using FEA decreases gradually and in a more uniform manner compared to the values obtained using DNV. The conservativeness of the DNV method with high percentage differences, when compared to the FEM, was anticipated, as the DNV code is recommended for material grades of API 5L X42 to API 5L X65 only.

Of the failure pressures, $58.4 \%$ have a percentage difference of greater than $10 \%$ when compared to the failure pressures obtained using FEM, as illustrated in the probability distribution function in Figure 12. The percentage difference between the results obtained using FEA and DNV was calculated using Equation (7).

$$
\text { Percentage Difference }=\frac{P_{n f, D N V}-P_{n f, F E A}}{P_{n f, F E A}}
$$




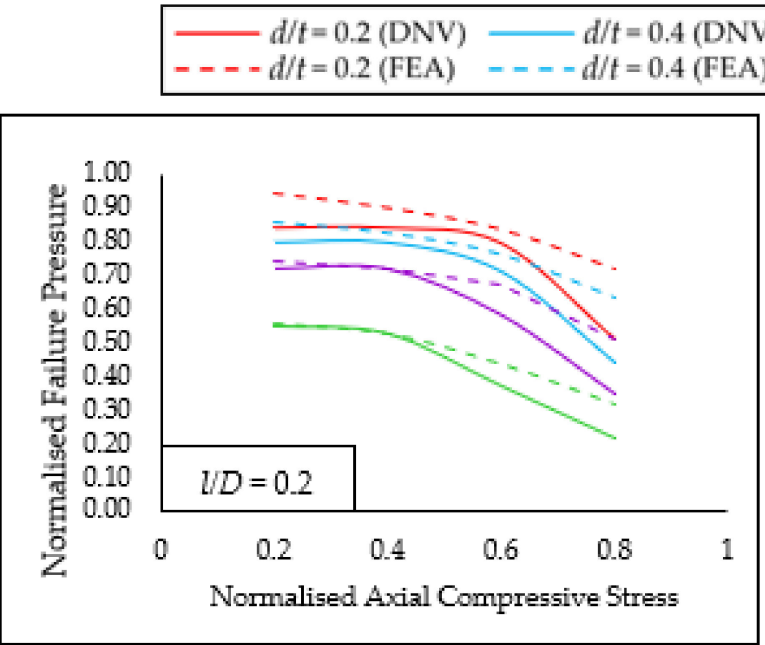

(a)

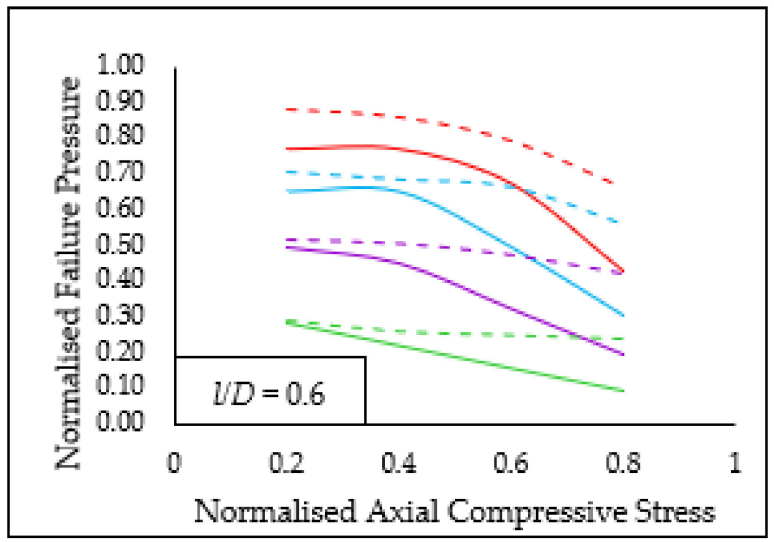

(c)
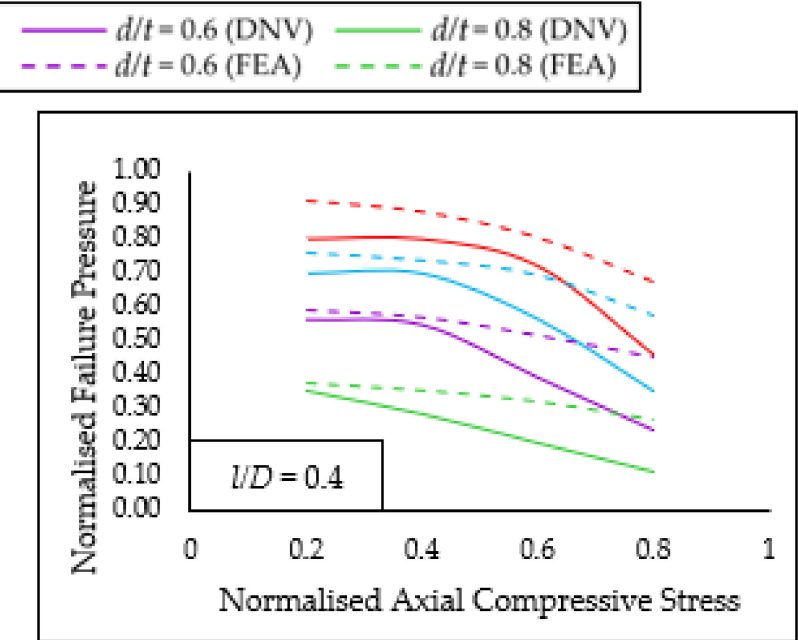

(b)

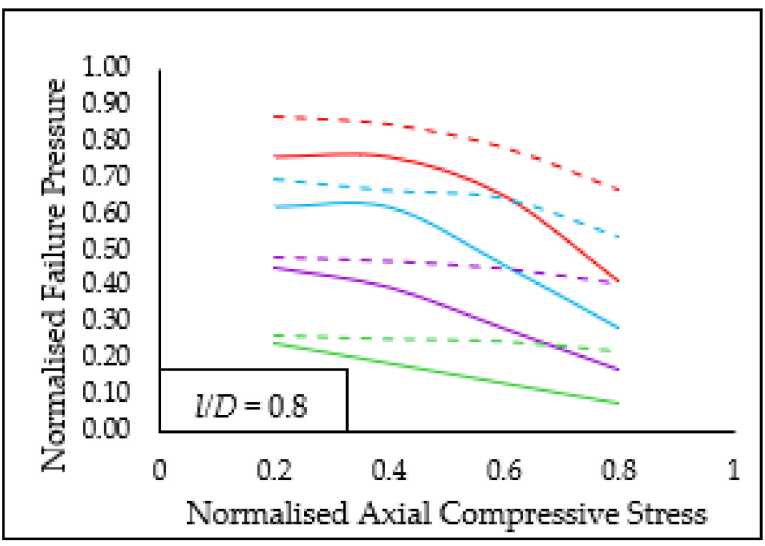

(d)

Figure 11. (a) Normalized failure pressure predictions of API 5L X80 pipe using FEA and DNV subjected to internal pressure and axial compressive stress for a normalised defect length of (a) 0.2 ; (b) 0.4 ; (c) 0.6 ; and (d) 0.8 .

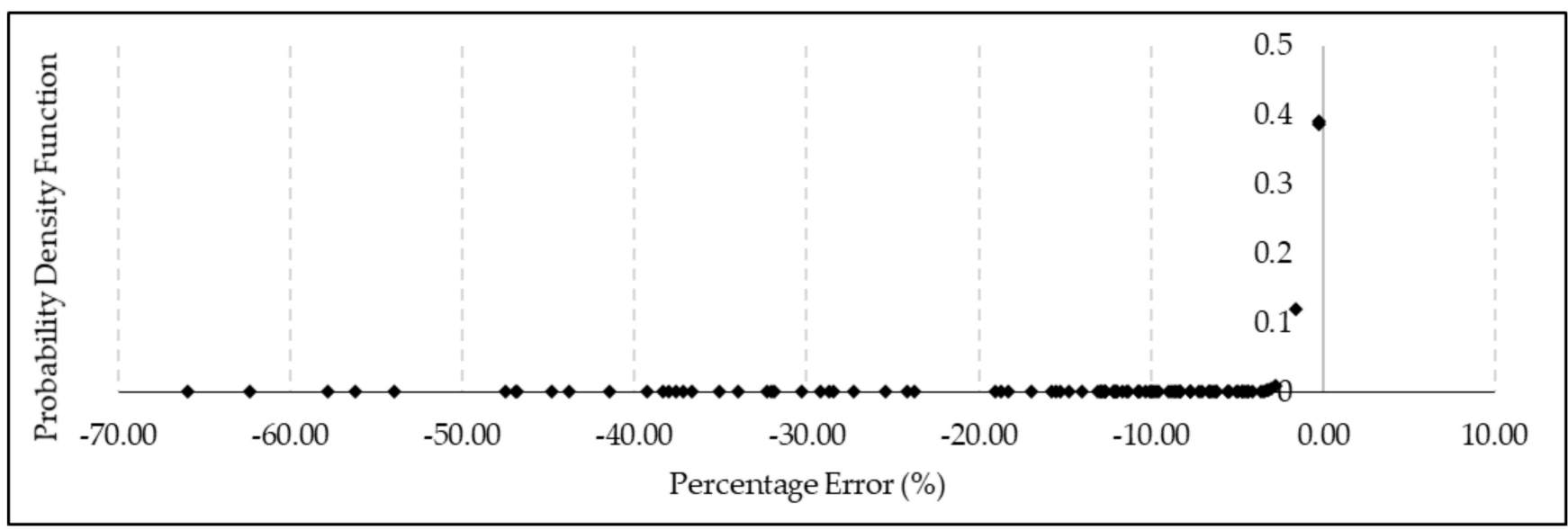

Figure 12. Probability density function of normalized failure pressure predictions using DNV method when compared to FEM for API 5L X80 pipe subjected to internal pressure and axial compressive stress. 


\subsection{Development of the ANN for the Failure Pressure Prediction of Pipe with Single Corrosion Defects}

\subsubsection{Generation of the ANN Training Data}

The failure pressures of pipes with single corrosion defect obtained using FEA were normalised by the intact pressure of the pipe before training the ANN. The intact pressure of the pristine pipe was obtained using FEM. To ensure a good correlation between the simulated model and theoretical calculation, the intact pressure value was compared with the maximum hoop stress theory represented by Equation (8). Based on this theory, the intact pressure of the pristine pipe is $51.3 \mathrm{MPa}$ and the intact pressure of the same pipe obtained using FEM was $50.32 \mathrm{MPa}$, with a percentage difference of $1.9 \%$ between these values.

Eighty-one sets of training data were used to train the ANN, as tabulated in Table 5. The normalised defect depth, length, axial compressive stress and normalised failure pressure are represented by $d / t, 1 / D, \sigma_{c} / \sigma_{y}$, and $P_{n f, F E A}$ respectively.

$$
P_{i}=\frac{\sigma_{U T S} t}{r_{i}}
$$

Table 5. ANN training data.

\begin{tabular}{cccccccccccc}
\hline$d / t$ & $\boldsymbol{l} / \boldsymbol{D}$ & $\sigma_{c} / \sigma_{\boldsymbol{y}}$ & $\boldsymbol{P}_{\text {fn, FEA }}$ & $d / \boldsymbol{t}$ & $\boldsymbol{l} / \boldsymbol{D}$ & $\sigma_{c} / \sigma_{\boldsymbol{y}}$ & $\boldsymbol{P}_{f n, F E A}$ & $d / \boldsymbol{t}$ & $\boldsymbol{l} \boldsymbol{D}$ & $\sigma_{c} / \sigma_{y}$ & $\boldsymbol{P}_{f n, F E A}$ \\
\hline 0.0 & 0.0 & 0.0 & 1.00 & 0.4 & 0.4 & 0.2 & 0.76 & 0.6 & 0.6 & 0.6 & 0.47 \\
0.2 & 0.2 & 0.0 & 0.95 & 0.4 & 0.4 & 0.4 & 0.74 & 0.6 & 0.6 & 0.8 & 0.42 \\
0.2 & 0.2 & 0.2 & 0.94 & 0.4 & 0.4 & 0.6 & 0.70 & 0.6 & 0.8 & 0.0 & 0.48 \\
0.2 & 0.2 & 0.4 & 0.90 & 0.4 & 0.4 & 0.8 & 0.58 & 0.6 & 0.8 & 0.2 & 0.48 \\
0.2 & 0.2 & 0.6 & 0.84 & 0.4 & 0.6 & 0.0 & 0.72 & 0.6 & 0.8 & 0.4 & 0.47 \\
0.2 & 0.2 & 0.8 & 0.72 & 0.4 & 0.6 & 0.2 & 0.71 & 0.6 & 0.8 & 0.6 & 0.45 \\
0.2 & 0.4 & 0.0 & 0.91 & 0.4 & 0.6 & 0.4 & 0.69 & 0.6 & 0.8 & 0.8 & 0.41 \\
0.2 & 0.4 & 0.2 & 0.91 & 0.4 & 0.6 & 0.6 & 0.66 & 0.8 & 0.2 & 0.0 & 0.58 \\
0.2 & 0.4 & 0.4 & 0.88 & 0.4 & 0.6 & 0.8 & 0.56 & 0.8 & 0.2 & 0.2 & 0.56 \\
0.2 & 0.4 & 0.6 & 0.80 & 0.4 & 0.8 & 0.0 & 0.71 & 0.8 & 0.2 & 0.4 & 0.52 \\
0.2 & 0.4 & 0.8 & 0.68 & 0.4 & 0.8 & 0.2 & 0.70 & 0.8 & 0.2 & 0.6 & 0.44 \\
0.2 & 0.6 & 0.0 & 0.89 & 0.4 & 0.8 & 0.4 & 0.66 & 0.8 & 0.2 & 0.8 & 0.41 \\
0.2 & 0.6 & 0.2 & 0.88 & 0.4 & 0.8 & 0.6 & 0.64 & 0.8 & 0.4 & 0.0 & 0.38 \\
0.2 & 0.6 & 0.4 & 0.86 & 0.4 & 0.8 & 0.8 & 0.54 & 0.8 & 0.4 & 0.2 & 0.38 \\
0.2 & 0.6 & 0.6 & 0.79 & 0.6 & 0.2 & 0.0 & 0.75 & 0.8 & 0.4 & 0.4 & 0.35 \\
0.2 & 0.6 & 0.8 & 0.66 & 0.6 & 0.2 & 0.2 & 0.74 & 0.8 & 0.4 & 0.6 & 0.32 \\
0.2 & 0.8 & 0.0 & 0.87 & 0.6 & 0.2 & 0.4 & 0.72 & 0.8 & 0.4 & 0.8 & 0.27 \\
0.2 & 0.8 & 0.2 & 0.87 & 0.6 & 0.2 & 0.6 & 0.68 & 0.8 & 0.6 & 0.0 & 0.31 \\
0.2 & 0.8 & 0.4 & 0.85 & 0.6 & 0.2 & 0.8 & 0.51 & 0.8 & 0.6 & 0.2 & 0.29 \\
0.2 & 0.8 & 0.6 & 0.78 & 0.6 & 0.4 & 0.0 & 0.59 & 0.8 & 0.6 & 0.4 & 0.26 \\
0.2 & 0.8 & 0.8 & 0.66 & 0.6 & 0.4 & 0.2 & 0.59 & 0.8 & 0.6 & 0.6 & 0.25 \\
0.4 & 0.2 & 0.0 & 0.87 & 0.6 & 0.4 & 0.4 & 0.57 & 0.8 & 0.6 & 0.8 & 0.24 \\
0.4 & 0.2 & 0.2 & 0.86 & 0.6 & 0.4 & 0.6 & 0.51 & 0.8 & 0.8 & 0.0 & 0.28 \\
0.4 & 0.2 & 0.4 & 0.83 & 0.6 & 0.4 & 0.8 & 0.45 & 0.8 & 0.8 & 0.2 & 0.27 \\
0.4 & 0.2 & 0.6 & 0.76 & 0.6 & 0.6 & 0.0 & 0.53 & 0.8 & 0.8 & 0.4 & 0.26 \\
0.4 & 0.2 & 0.8 & 0.63 & 0.6 & 0.6 & 0.2 & 0.51 & 0.8 & 0.8 & 0.6 & 0.23 \\
0.4 & 0.4 & 0.0 & 0.76 & 0.6 & 0.6 & 0.4 & 0.50 & 0.8 & 0.8 & 0.8 & 0.23 \\
\hline & & & & & & & & & & &
\end{tabular}

4.2.2. Determination of the Number of Hidden Layers and Nodes in Each Layer

The optimum number of hidden layers and neurons in each layer of the ANN were determined based on the regression analysis of the model. Eight models were developed and their corresponding coefficient of determination $\left(R^{2}\right)$ was recorded. Initially, the ANN model was trained using one hidden layer with one node. For each subsequent ANN model, the number of neurons in the first hidden layer was increased by 1 . When the number of neurons in a hidden layer reaches 3 , a new hidden layer with one node was added to the subsequent model. The maximum number of hidden layers and neurons in each hidden 
layer was set at three, to ensure that the empirical solution that was developed was not overly complex. Table 6 summarizes the $R^{2}$ value obtained for each model developed.

Table 6. Performances of the developed ANN models based on their coefficient of the determinant.

\begin{tabular}{cccccc}
\hline Model & $\begin{array}{c}\text { No. of Hidden } \\
\text { Layers }\end{array}$ & $\begin{array}{c}\text { No. of Neurons in } \\
\text { Hidden Layer 1 }\end{array}$ & $\begin{array}{c}\text { No. of Neurons in } \\
\text { Hidden Layer 2 }\end{array}$ & $\begin{array}{c}\text { No. of Neurons in } \\
\text { Hidden Layer 3 }\end{array}$ & $\boldsymbol{R}^{\mathbf{2}}$ Value \\
\hline 1 & 1 & 1 & - & - & 0.93 \\
2 & 1 & 2 & - & - & 0.93 \\
3 & 1 & 3 & - & - & 0.95 \\
4 & 2 & 3 & 1 & - & 0.97 \\
5 & 2 & 3 & 3 & - & 0.99 \\
6 & 2 & 3 & 3 & 2 & 0.99 \\
7 & 3 & 3 & 3 & 3 & 0.98 \\
9 & 3 & 3 & 3 & & 0.94 \\
\hline
\end{tabular}

Upon comparing the $R^{2}$ values of the developed models, it was found that Models 5 and 6 produced $R^{2}$ values closest to 1.00 , which were 0.99 . Both Models 5 and 6 consist of two hidden layers and 3 neurons in the first hidden layer. However, the number of neurons in the second hidden layer of Model 5 is less than that of Model 6. Hence, Model 5 was utilised for the development of an empirical solution, to ensure the simplicity of the equations, without compromising the accuracy of the outcome.

Figure 13 illustrates the regression plots generated by MathWorks MatlabR2019 for Model 5. The four plots in the figure represent the training, validation, testing, and the combination of all the three plots. The linear regression line of best fit between the output of the ANN and the desired output value is represented by the solid lines in the plot, with dashed lines representing perfect results. In Figure 13, it is observed that the solid lines and dashed line in each plot almost overlap completely, indicating that Model 5 is highly capable of outputting results that are similar to that of the training data.

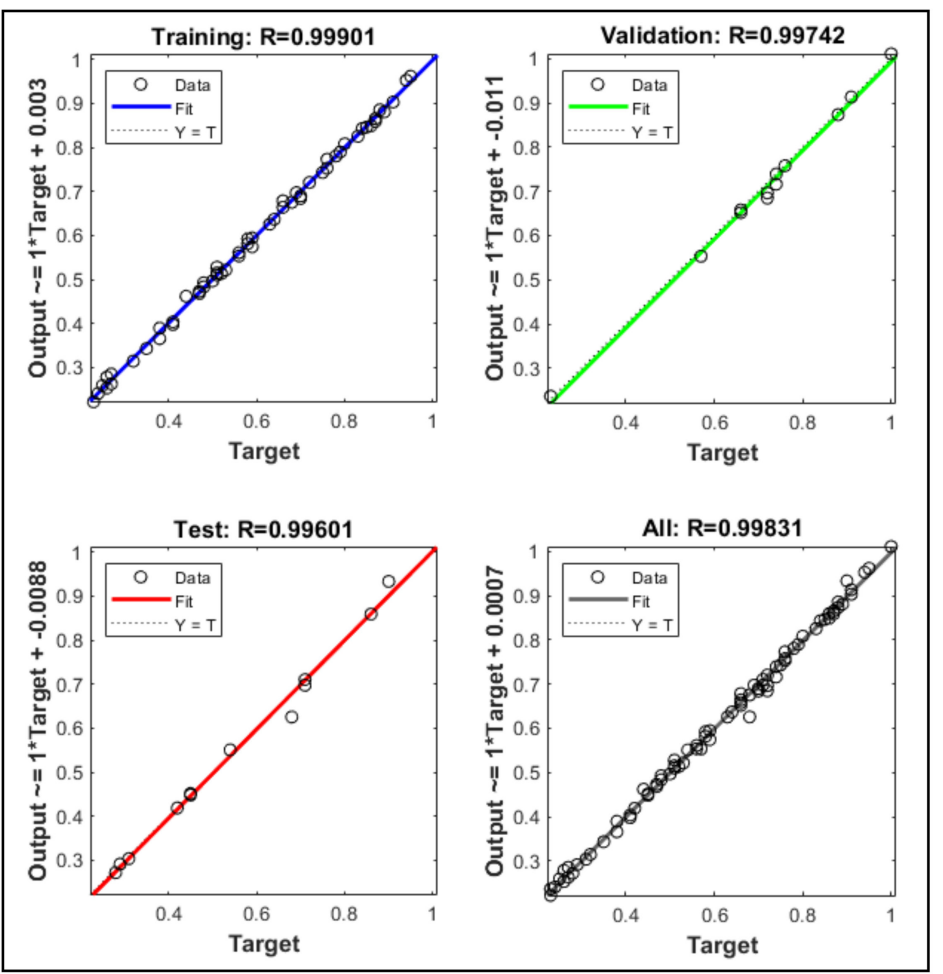

Figure 13. Regression plots of Model 5. 
4.3. Development of an Empirical Equation for the Failure Pressure Prediction of Corroded Pipeline with a Single Defect

The weights and biases of Model 5 were used to develop an empirical equation to predict the failure pressure of a pipe with a single corrosion defect. The weights and biases of the trained ANN model, as illustrated in Figure 14, can be represented in a matrix form. Equations (9)-(11) represent the matrix of the ANN model.

$$
\begin{aligned}
{\left[\begin{array}{l}
h_{1,1} \\
h_{1,2} \\
h_{1,3}
\end{array}\right] } & =\left[\begin{array}{lll}
w_{i, 1} & w_{i, 4} & w_{i, 7} \\
w_{i, 2} & w_{i, 5} & w_{i, 8} \\
w_{i, 3} & w_{i, 6} & w_{i, 9}
\end{array}\right]\left[\begin{array}{l}
(d / t)_{n} \\
(l / d)_{n} \\
\left(\sigma_{c} / \sigma_{y}\right)_{n}
\end{array}\right]+\left[\begin{array}{l}
b_{1,1} \\
b_{1,2} \\
b_{1,3}
\end{array}\right] \\
{\left[\begin{array}{l}
h_{2,1} \\
h_{2,2}
\end{array}\right] } & =\left[\begin{array}{lll}
w_{1,1} & w_{1,3} & w_{1,5} \\
w_{1,2} & w_{1,4} & w_{1,6}
\end{array}\right]\left[\begin{array}{l}
a\left(h_{1,1}\right) \\
a\left(h_{1,2}\right) \\
a\left(h_{1,3}\right)
\end{array}\right]+\left[\begin{array}{l}
b_{2,1} \\
b_{2,2}
\end{array}\right] \\
o_{n} & =f\left(\left[\begin{array}{ll}
w_{2,1} & w_{2,2}
\end{array}\right]\left[\begin{array}{l}
a\left(h_{2,1}\right) \\
a\left(h_{2,2}\right)
\end{array}\right]+\left[b_{o}\right]\right)
\end{aligned}
$$

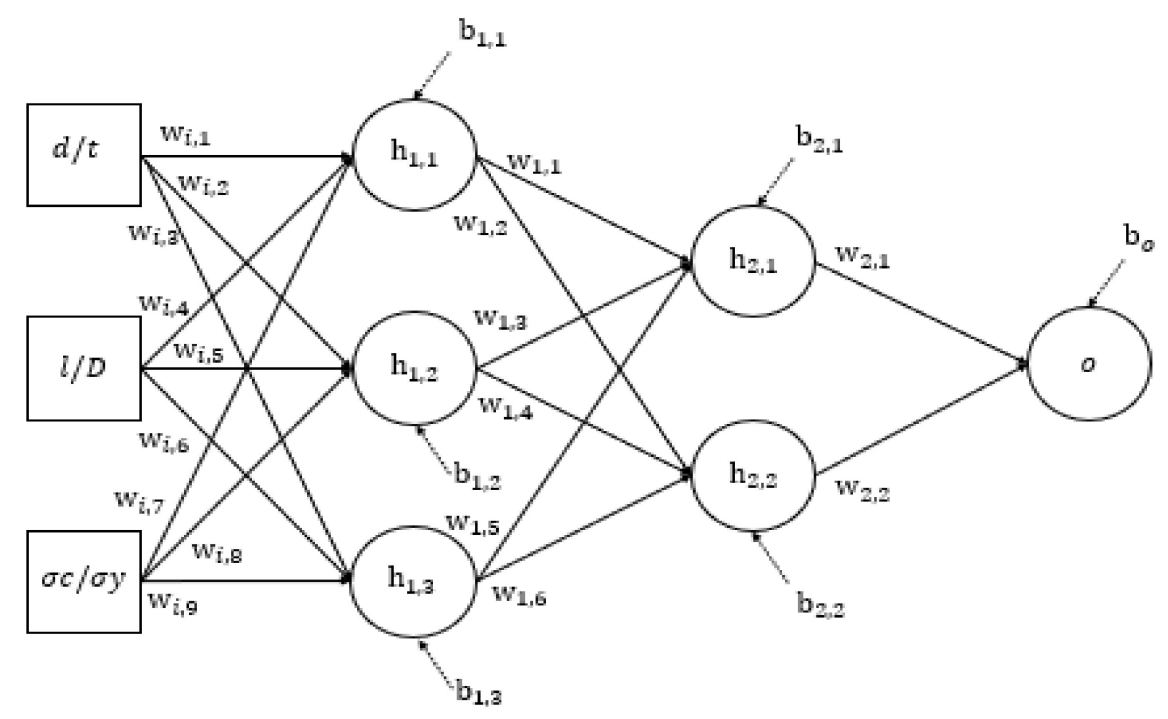

Figure 14. Architecture of the ANN model.

The input values of the ANN are normalised by the ANN model so that the normalised input value, $i_{n}$, falls within the range of -1 to 1 before the values are transferred to the first hidden layer. Hence, the inputs need to be normalised using Equation (12) before being used. Likewise, the output values that were used to train the ANN model were normalised to range between the values of -1 and 1 . Hence, the final output, $o$, must be denormalized using Equation (13), to obtain the failure pressure of the corroded pipe.

$$
\begin{aligned}
& i_{n}=\frac{\left(i_{n, \max }-i_{n, \min }\right)\left(i-i_{\text {min }}\right)}{\left(i_{\text {max }}-i_{\text {min }}\right)}+i_{n, \text { min }} \\
& o=\frac{\left(o_{n}-o_{n, \min }\right)\left(o_{\text {max }}-o_{\text {min }}\right)}{\left(o_{n, \max }-o_{n, \min }\right)}+o_{\text {min }}
\end{aligned}
$$

Upon training the ANN model, specific constant values were obtained for the weights and biases as represented by Equations (14)-(16).

$$
\left[\begin{array}{l}
h_{1,1} \\
h_{1,2} \\
h_{1,3}
\end{array}\right]=\left[\begin{array}{ccc}
-0.24336 & -0.027758 & 2.4948 \\
0.26663 & 0.012313 & 0.0093227 \\
-0.023211 & 1.3349 & 0.18235
\end{array}\right]\left[\begin{array}{c}
(d / t)_{n} \\
(l / d)_{n} \\
\left(\sigma_{c} / \sigma_{y}\right)_{n}
\end{array}\right]+\left[\begin{array}{c}
-1.7819 \\
0.0033338 \\
1.491
\end{array}\right]
$$




$$
\begin{aligned}
{\left[\begin{array}{l}
h_{2,1} \\
h_{2,2}
\end{array}\right]=\left[\begin{array}{lll}
0.22303 & -2.1421 & -1.2816 \\
0.27615 & 0.49941 & -0.15404
\end{array}\right]\left[\begin{array}{l}
a\left(h_{1,1}\right) \\
a\left(h_{1,2}\right) \\
a\left(h_{1,3}\right)
\end{array}\right]+\left[\begin{array}{c}
2.0577 \\
0.57701
\end{array}\right] } \\
o_{n}=f\left(\left[\begin{array}{ll}
1.7285 & -1.8549
\end{array}\right]\left[\begin{array}{l}
a\left(h_{2,1}\right) \\
a\left(h_{2,2}\right)
\end{array}\right]+[-0.37438]\right)
\end{aligned}
$$

The steps involved in predicting the failure pressure of the corroded pipeline with a single corrosion defect is summarised below:

Step 1: Normalisation of input parameters

$$
\begin{aligned}
(d / t)_{n} & =\frac{2(d / t)_{i}}{0.8}-1 \\
(l / d)_{n} & =\frac{2(l / d)_{i}}{0.8}-1 \\
\left(\sigma_{c} / \sigma_{y}\right)_{n} & =\frac{2\left(\sigma_{c} / \sigma_{y}\right)_{i}}{0.8}-1
\end{aligned}
$$

Step 2: Calculation of the normalised output value

$$
\begin{aligned}
a\left(h_{1,1}\right) & =\frac{2}{1+e^{-2\left(h_{1,1}\right)}}-1 \\
a\left(h_{1,2}\right) & =\frac{2}{1+e^{-2\left(h_{1,2}\right)}}-1 \\
a\left(h_{1,3}\right) & =\frac{2}{1+e^{-2\left(h_{1,3}\right)}}-1 \\
a\left(h_{2,1}\right) & =\frac{2}{1+e^{-2\left(h_{2,1}\right)}}-1 \\
a\left(h_{2,2}\right) & =\frac{2}{1+e^{-2\left(h_{2,2}\right)}}-1 \\
f\left(o_{n}\right)=1.7285 a\left(h_{2,1}\right)-1.8549 a\left(h_{2,2}\right)-0.37438 & \\
o_{n} & =f\left(o_{n}\right)
\end{aligned}
$$

Step 3: Denormalization of the output value

$$
P_{n f, E q}=0.387425 o_{n}+0.612575
$$

Step 4: Calculation of the failure pressure

$$
\begin{gathered}
P_{i}=\frac{\sigma * U T S}{r_{i}} t \\
P_{f, E q}=P_{n f, E q} * P_{i}
\end{gathered}
$$

\subsection{Evaluation of the New Corroded Pipeline Failure Pressure Assessment Method}

Since the equations in the newly developed corrosion assessment method were extracted from the ANN, the $R^{2}$ value of the new method is similar to that of the ANN, which is 0.997 . This indicates that the method results in failure pressure predictions that are very close to the results obtained using FEA, which was used as the training data for the ANN model. Based on the maximum hoop stress theory, the intact pressure of the pristine pipe model used in this study was $51.3 \mathrm{MPa}$, while the intact pressure obtained using FEM was $50.32 \mathrm{MPa}$. Using the newly developed failure pressure assessment method, the intact 
pressure of the pristine pipe was calculated to be $51.86 \mathrm{MPa}$. The comparison of the intact pressure values obtained using the three methods is summarised in Table 7 . The percentage difference between the failure pressure obtained using the maximum hoop stress and the new corrosion assessment method is $1.09 \%$, while the percentage difference between the failure pressure obtains using FEM and the new corrosion assessment method is $3.06 \%$. This indicates a good correlation between the three methods.

Table 7. Comparison of the intact pressure values of the pristine pipe.

\begin{tabular}{ccccc}
\hline $\begin{array}{c}\text { Maximum Hoop } \\
\begin{array}{c}\text { Stress Theory [A] } \\
(\mathbf{M P a})\end{array}\end{array}$ & FEM [B] (MPa) & $\begin{array}{c}\text { Newly Developed } \\
\text { Method [C] (MPa) }\end{array}$ & $\begin{array}{c}\text { Percentage Difference } \\
\text { between [A] and [C] } \\
(\mathbf{\%})\end{array}$ & $\begin{array}{c}\text { Percentage Difference } \\
\text { between [B] and [C] } \\
(\%)\end{array}$ \\
\hline 51.30 & 50.32 & 51.86 & 1.09 & 3.06 \\
\hline
\end{tabular}

The probability distribution in Figure 15 depicts the percentage difference between the failure pressure predicted using FEM and the new method for the same parameters used to train the ANN. The percentage of differences fall within the range of $-7.37 \%$ to $8.37 \%$, with a standard deviation of 2.36 . Based on the probability distribution function in Figure 15, it is observed that the percentage differences between the methods fall within four standard deviations of the mean. This indicates that the probability of obtaining a failure pressure with a percentage error of greater than $9.44 \%$ is 1 in 15,787 .

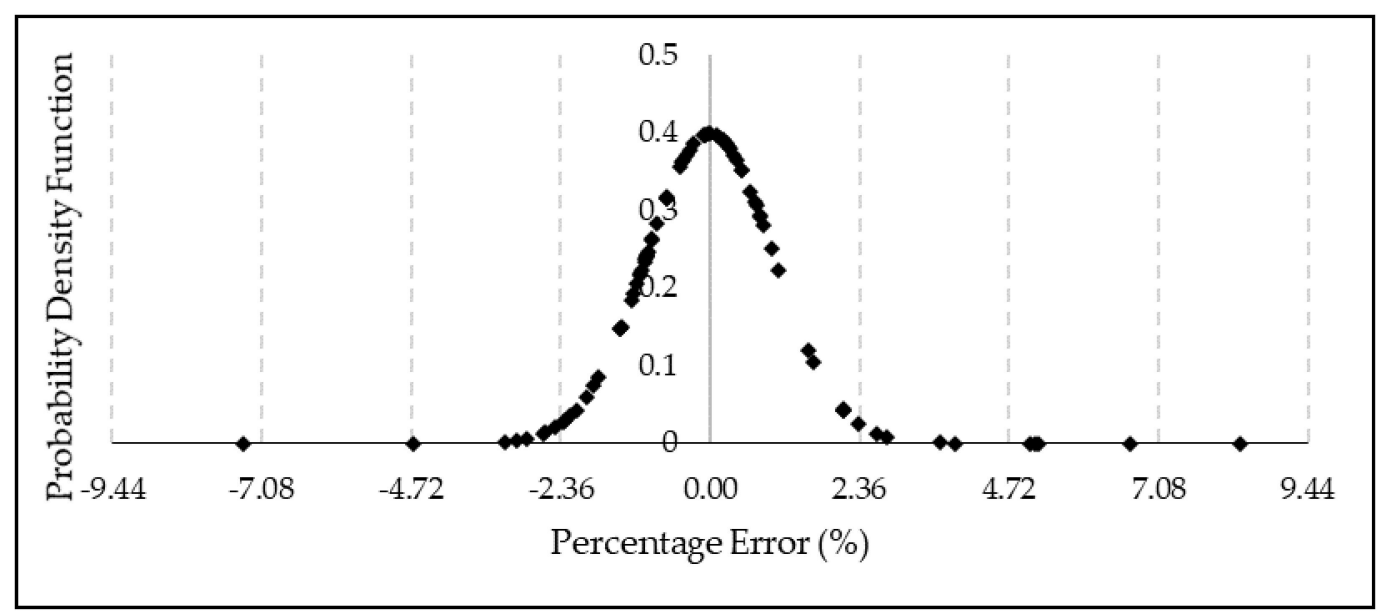

Figure 15. Probability distribution of the percentage error obtained using the newly developed failure pressure prediction method and FEM based on the parameters of the ANN training data.

To ensure that the new method performed well with data that was not included in the training of the ANN, results from actual full-scale burst tests and FEA for a set of arbitrary data were used to validate the new failure pressure prediction method. The actual full-scale burst tests were carried out using internal pressure loading only and the results of the burst tests and validation of the new equation are summarised in Table 8. Due to the lack of data on actual full-scale burst tests of high toughness pipes subjected to internal pressure and axial compressive stress, FEM was used to further validate the new failure pressure prediction method based on a set of arbitrary data for API 5L X80 material with a $\sigma^{*} U T S$ value of $718 \mathrm{MPa}$. Table 9 summarises the parametric details of the arbitrary data, the failure pressure predictions using FEM and the new method, and the percentage difference between the methods. A negative percentage difference indicates a conservative prediction, while a positive value indicates an overestimation of the failure pressure obtained using the new corrosion assessment method. 
Table 8. Validation of newly developed failure pressure prediction method against actual full-scale burst tests for high-grade pipes subjected to internal pressure only, data from [32].

\begin{tabular}{|c|c|c|c|c|c|c|c|}
\hline Data No. & Grade & $\sigma^{*}$ uTs (MPa) & $d / t$ & $l / D$ & $\begin{array}{l}\text { Failure Pressure } \\
\text { (MPa) }\end{array}$ & $P_{f, E q}(\mathrm{MPa})$ & $\begin{array}{c}\text { Percentage } \\
\text { Difference (\%) }\end{array}$ \\
\hline 68 & X80 & 731 & 0.47 & 0.09 & 22.75 & 23.03 & 1.23 \\
\hline 69 & $\mathrm{X} 80$ & 684 & 0.67 & 0.09 & 20.61 & 19.72 & -4.32 \\
\hline 70 & X80 & 740 & 0.77 & 0.50 & 9.65 & 9.00 & -6.74 \\
\hline 71 & $\mathrm{X} 80$ & 740 & 0.37 & 0.50 & 18.28 & 19.04 & 4.16 \\
\hline 72 & X80 & 740 & 0.09 & 0.50 & 24.69 & 24.00 & -2.79 \\
\hline 73 & X80 & 740 & 0.78 & 0.48 & 5.99 & 6.15 & 2.67 \\
\hline 74 & $\mathrm{X} 80$ & 740 & 0.40 & 0.48 & 12.08 & 12.81 & 6.04 \\
\hline 75 & $\mathrm{X} 80$ & 740 & 0.11 & 0.48 & 16.69 & 16.28 & -2.46 \\
\hline 76 & X100 & 886 & 0.50 & 0.46 & 20.14 & 21.15 & 5.01 \\
\hline 79 & X100 & 886 & 0.50 & 0.77 & 18.06 & 19.09 & 5.70 \\
\hline
\end{tabular}

Table 9. Comparison of pipe failure pressure prediction using FEM and the newly developed method for API 5L X80 pipes subjected to internal pressure and axial compressive stress.

\begin{tabular}{cccccc}
\hline $\boldsymbol{d} / \boldsymbol{t}$ & $\boldsymbol{l} / \boldsymbol{D}$ & $\sigma_{\boldsymbol{c}} / \sigma_{\boldsymbol{y}}$ & $\boldsymbol{P}_{\boldsymbol{n f}, \boldsymbol{F E A}}$ & $\boldsymbol{P}_{\boldsymbol{n f}, \boldsymbol{E} \boldsymbol{q}}$ & $\begin{array}{c}\text { Percentage } \\
\text { Difference (\%) }\end{array}$ \\
\hline 0.1 & 0.3 & 0.3 & 0.96 & 0.97 & 1.26 \\
0.1 & 0.3 & 0.6 & 0.84 & 0.86 & 2.95 \\
0.1 & 0.7 & 0.3 & 0.93 & 0.93 & -0.26 \\
0.1 & 0.9 & 0.3 & 0.93 & 0.92 & -1.19 \\
0.2 & 0.5 & 0.32 & 0.88 & 0.88 & -0.22 \\
0.2 & 0.7 & 0.45 & 0.84 & 0.84 & -0.09 \\
0.3 & 0.3 & 0.3 & 0.86 & 0.86 & 0.51 \\
0.3 & 0.3 & 0.6 & 0.77 & 0.77 & -1.00 \\
0.35 & 0.7 & 0.6 & 0.69 & 0.68 & 1.85 \\
0.35 & 1.1 & 0.35 & 0.7 & 0.71 & 3.91 \\
0.35 & 1.1 & 0.6 & 0.64 & 0.67 & 0.15 \\
0.45 & 1.1 & 0.45 & 0.59 & 0.61 & -2.07 \\
0.4 & 0.5 & 0.32 & 0.72 & 0.72 & -0.91 \\
0.45 & 0.7 & 0.6 & 0.6 & 0.60 & -5.84 \\
0.55 & 0.3 & 0.6 & 0.62 & 0.60 & 7.53 \\
0.55 & 0.5 & 0.35 & 0.58 & 0.57 & 0.17 \\
0.7 & 0.5 & 0.25 & 0.45 & 0.52 & -6.86 \\
0.7 & 0.7 & 0.35 & 0.35 & 0.38 & -6.82 \\
0.8 & 0.2 & 0.5 & 0.49 & 0.49 & -2.86 \\
0.8 & 0.3 & 0.35 & 0.45 & 0.42 & -1.26 \\
0.8 & 0.3 & 0.6 & 0.4 & 0.37 & -1.59 \\
0.8 & 0.7 & 0.25 & 0.28 & 0.27 & \\
0.8 & 0.7 & 0.5 & 0.26 & 0.26 & 0.25 \\
0.8 & 0.7 & 0.6 & 0.25 & & \\
\hline
\end{tabular}

Based on Tables 8 and 9, the percentage difference between the two methods ranges from $-6.86 \%$ to $7.53 \%$. Hence, it is evident that the newly developed failure pressure predictions conform to the four-sigma rule where the predicted failure pressures fall within the four-sigma range of $9.44 \%$. However, this is only true for normalised defect depths of 0.00 to 0.80 , normalised defect lengths of 0.00 to 1.10 , normalised axial compressive stress from 0.00 to 0.80 , and pipe true ultimate tensile strengths values ranging from 684 to $886 \mathrm{MPa}$.

\subsection{Extensive Parametric Studies Using the Newly Developed Assessment Equation}

The newly developed failure pressure prediction method was used to conduct an extensive parametric study to investigate the effects of the defect depth, defect length and axial compressive stress acting on an API 5L X80 corroded pipe with single corrosion 
defect. The parameters used in this study are tabulated in Table 10. The failure pressure of pipes subjected to internal pressure was only used as reference data to study the effects of normalised defect length, normalised defect depth, and normalised axial compressive stress on the normalised failure pressure of a pipe when axial compressive stress was introduced.

Table 10. Results of the extensive parametric study using the new corrosion assessment method for API 5L X80 pipe with single corrosion defect.

\begin{tabular}{|c|c|c|c|c|c|c|}
\hline \multirow{2}{*}{$\begin{array}{c}\text { Normalised } \\
\text { Defect Depth }(d / t)\end{array}$} & \multirow{2}{*}{$\begin{array}{l}\text { Normalised Defect } \\
\text { Length }(l / D)\end{array}$} & \multicolumn{5}{|c|}{ Normalised Failure Pressure $\left(P_{n f, E q}\right)$} \\
\hline & & $0.00 \sigma_{y}$ & $0.20 \sigma_{y}$ & $0.40 \sigma_{y}$ & $0.60 \sigma_{y}$ & $0.80 \sigma_{y}$ \\
\hline 0.00 & 0.00 & 1.00 & 1.00 & 1.00 & 0.89 & 0.74 \\
\hline \multirow{7}{*}{0.05} & 0.05 & 1.00 & 1.00 & 1.00 & 0.89 & 0.73 \\
\hline & 0.20 & 1.00 & 1.00 & 1.00 & 0.89 & 0.74 \\
\hline & 0.40 & 0.99 & 0.99 & 0.97 & 0.87 & 0.73 \\
\hline & 0.60 & 0.97 & 0.97 & 0.95 & 0.86 & 0.72 \\
\hline & 0.80 & 0.96 & 0.96 & 0.94 & 0.86 & 0.72 \\
\hline & 1.00 & 0.96 & 0.95 & 0.94 & 0.85 & 0.71 \\
\hline & 1.10 & 0.95 & 0.95 & 0.93 & 0.85 & 0.71 \\
\hline \multirow{7}{*}{0.20} & 0.05 & 0.97 & 0.97 & 0.95 & 0.86 & 0.71 \\
\hline & 0.20 & 0.96 & 0.95 & 0.93 & 0.84 & 0.69 \\
\hline & 0.40 & 0.91 & 0.90 & 0.88 & 0.81 & 0.67 \\
\hline & 0.60 & 0.88 & 0.87 & 0.86 & 0.79 & 0.66 \\
\hline & 0.80 & 0.86 & 0.86 & 0.85 & 0.78 & 0.66 \\
\hline & 1.00 & 0.85 & 0.85 & 0.84 & 0.77 & 0.65 \\
\hline & 1.10 & 0.85 & 0.84 & 0.83 & 0.77 & 0.65 \\
\hline \multirow{7}{*}{0.40} & 0.05 & 0.90 & 0.90 & 0.88 & 0.80 & 0.66 \\
\hline & 0.20 & 0.86 & 0.85 & 0.82 & 0.75 & 0.62 \\
\hline & 0.40 & 0.77 & 0.76 & 0.74 & 0.68 & 0.58 \\
\hline & 0.60 & 0.72 & 0.71 & 0.70 & 0.65 & 0.56 \\
\hline & 0.80 & 0.70 & 0.69 & 0.68 & 0.63 & 0.55 \\
\hline & 1.00 & 0.68 & 0.68 & 0.67 & 0.63 & 0.54 \\
\hline & 1.10 & 0.68 & 0.67 & 0.66 & 0.62 & 0.54 \\
\hline \multirow{7}{*}{0.60} & 0.05 & 0.83 & 0.82 & 0.80 & 0.73 & 0.60 \\
\hline & 0.20 & 0.74 & 0.71 & 0.68 & 0.62 & 0.53 \\
\hline & 0.40 & 0.59 & 0.57 & 0.55 & 0.51 & 0.45 \\
\hline & 0.60 & 0.52 & 0.51 & 0.49 & 0.47 & 0.42 \\
\hline & 0.80 & 0.49 & 0.48 & 0.47 & 0.44 & 0.40 \\
\hline & 1.00 & 0.47 & 0.47 & 0.46 & 0.43 & 0.39 \\
\hline & 1.10 & 0.47 & 0.46 & 0.45 & 0.43 & 0.39 \\
\hline \multirow{7}{*}{0.80} & 0.05 & 0.74 & 0.72 & 0.69 & 0.63 & 0.52 \\
\hline & 0.20 & 0.59 & 0.55 & 0.51 & 0.46 & 0.39 \\
\hline & 0.40 & 0.39 & 0.36 & 0.34 & 0.31 & 0.28 \\
\hline & 0.60 & 0.30 & 0.29 & 0.27 & 0.25 & 0.24 \\
\hline & 0.80 & 0.27 & 0.26 & 0.25 & 0.23 & 0.22 \\
\hline & 1.00 & 0.25 & 0.24 & 0.23 & 0.22 & 0.21 \\
\hline & 1.10 & 0.25 & 0.24 & 0.23 & 0.21 & 0.20 \\
\hline
\end{tabular}

\subsubsection{Effects of Defect Length on the Failure Pressure of a Pipe}

Based on Figure 16, it was observed that for normalised defect lengths of 0.05 to 1.10, the failure pressure trend was similar for each value of normalised axial compressive stress for a constant normalised defect depth of 0.20. As the normalised defect length was increased from 0.05 to 1.10 for normalised axial compressive stress values of 0.00 to 0.80 , it was observed that the failure pressure decreased by a maximum of $12.69 \%$. This similar pattern was also observed for a normalised defect depth of 0.05 and 0.40 with a maximum normalised failure pressure decrease of $6.62 \%$ and $25.34 \%$ respectively. 


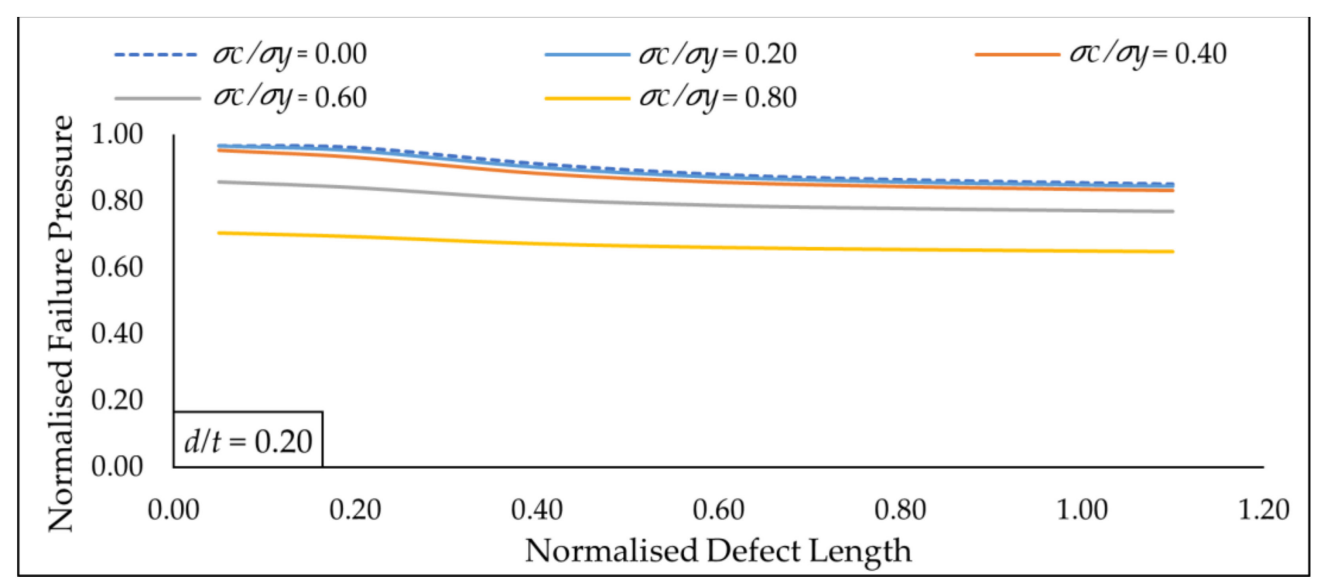

Figure 16. Normalized failure pressure predictions of the new assessment method against various normalized defect length for multiple axial compressive stress at a constant normalized defect depth of 0.20 .

This decrease is more significant as the normalised defect length is increased for normalised defect depth values of 0.60 and 0.80 . Under these conditions, the maximum decrease in failure pressure was $43.36 \%$ and $66.64 \%$, respectively, for normalised axial compressive stress values of 0.00 to 0.80 . A drastic decrease in the normalised failure pressure for normalised defect lengths of 0.00 to 0.80 was observed, indicating that the normalised defect length significantly influences the failure pressure of a pipe when the normalised defect depth ranges from 0.60 to 0.80 . For the case of normalised defect depth of 0.80 , the decrease in failure pressure is illustrated in Figure 17. Besides, it was also observed that the normalised failure pressure approaches a constant value as the normalised defect length increases from 0.80 to 1.10, as depicted in Figures 16 and 17.

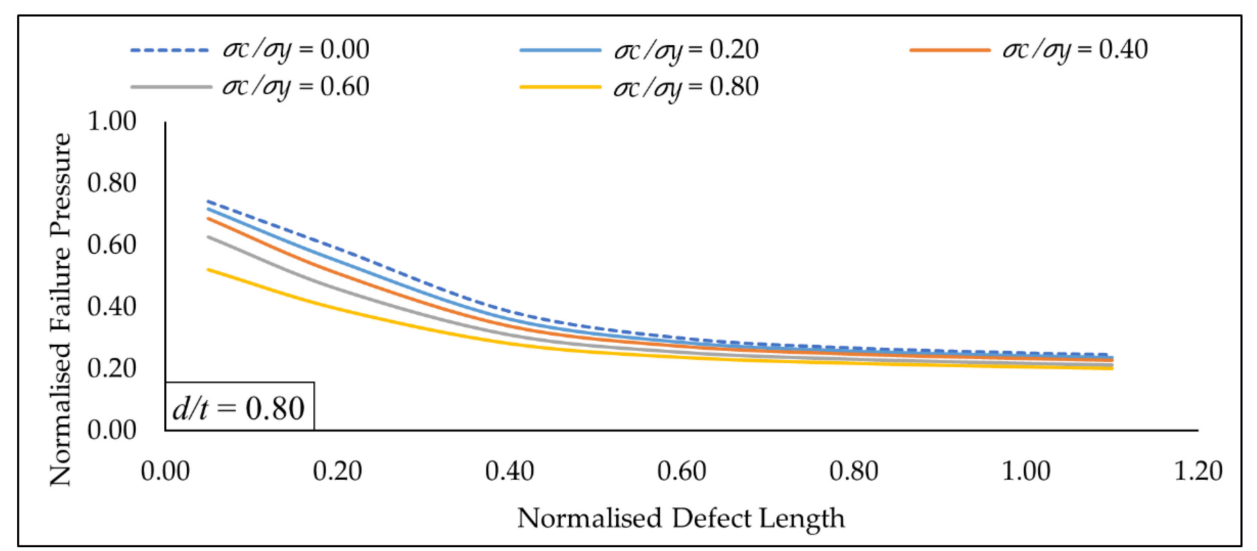

Figure 17. Normalized failure pressure predictions of the new assessment method against various normalized defect length for multiple axial compressive stress at a constant normalized defect depth of 0.80 .

Based on Figure 18, at a constant normalised axial compressive stress of 0.40 , the influence of normalised defect length on the decrease in normalised failure pressure can be observed in more detail as the normalised defect depths are increased from 0.05 to 0.80 . Since the decrease in normalised failure pressure was only $6.12 \%$ for a normalised defect depth of 0.05 when the normalised defect length was increased from 0.00 to 1.10 , it indicates that the influence of normalised defect length is insignificant under this condition as the decrease in normalised failure pressure was less than $10 \%$. As the normalised defect length was increased from 0.80 to 1.10 for each of the normalised defect depth values, it was observed that its influence on normalised failure pressure was also insignificant. The maximum drop in normalised failure pressure in this region was only $7.93 \%$. This suggests 
that for normalised defect depths of 0.20 to 0.80 , normalised defect lengths of 0.00 to 0.80 significantly influence the normalised failure pressure. This pattern was observed to be similar for all other values of normalised axial compressive stresses investigated in this parametric study.

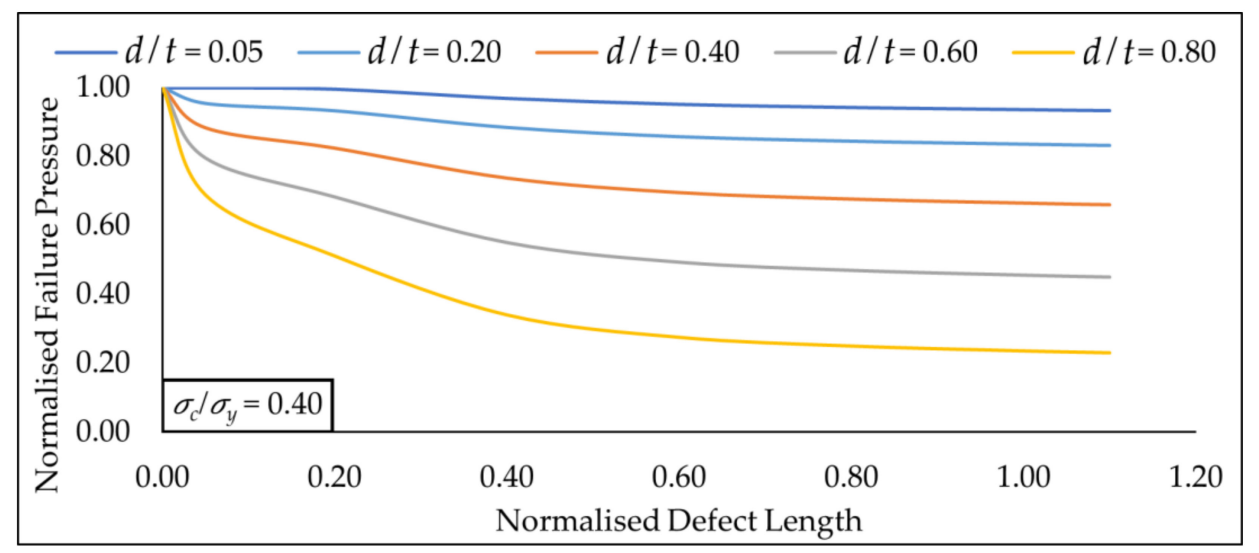

Figure 18. Normalized failure pressure predictions of the new assessment method against various normalized defect length for multiple normalised defect depths at constant normalized axial compressive stress of 0.40 .

\subsubsection{Effects of Defect Depth on the Failure Pressure of a Pipe}

Based on Figure 19, at a constant defect length of 0.60 , it was observed that the normalised failure pressure decreases drastically as the normalised defect depth was increased for normalised axial compressive stress values of 0.00 to 0.80 . The maximum normalised pressure drop based on normalised axial compressive stress values of 0.00 to 0.80 was observed to be $71.19 \%$. This indicates that the normalised defect depth has a high influence on the normalised failure pressure of a pipe. For shallow depths, the increase in normalised axial compressive stress from 0.00 to 0.80 causes a drastic reduction in the normalised failure pressure. As the normalised defect depth increases, this reduction in failure pressure shrinks by almost half the amount as the normalised defect length approaches 0.80 . This pattern was also observed for defect lengths of $0.05,0.20,0.40,0.80$, 1.00 and 1.10 .

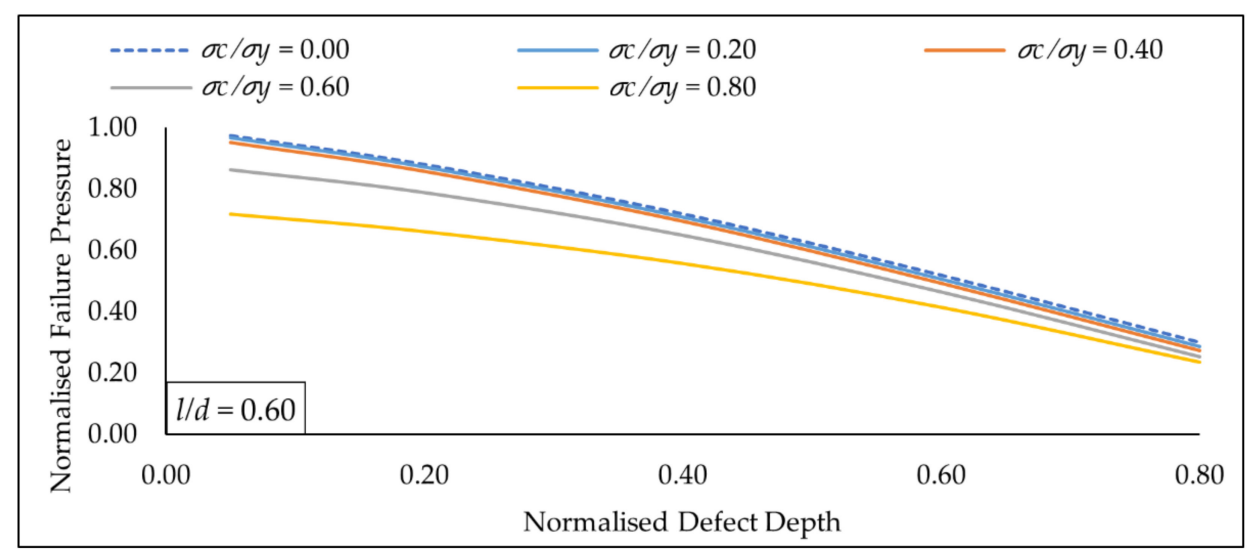

Figure 19. Normalized failure pressure predictions of the new assessment method against various normalized defect depth for multiple axial compressive stress at constant normalized defect length of 0.60 .

Based on Figure 20, at a constant normalised axial compressive stress of 0.40, the influence of normalised defect depth on the decrease in normalised failure pressure can be observed in more detail as the normalised defect lengths are increased from 0.05 to 
1.10. Generally, it was observed that the normalised failure pressure decreases gradually as the normalised defect depth was increased. The maximum normalised failure pressure reduction was observed to be $75.45 \%$ based on normalised defect length values of 0.0 to 1.1. As the normalised defect depth is increased from 0.0 to 0.8 , the decrease in failure pressure is more drastic for increasing values of normalised defect length. This indicates that the normalised defect depth greatly influences the normalised failure pressure of a pipe under axial loading and internal stress. This pattern was also observed for normalised axial compressive stress values of $0.2,0.6$, and 0.8 .

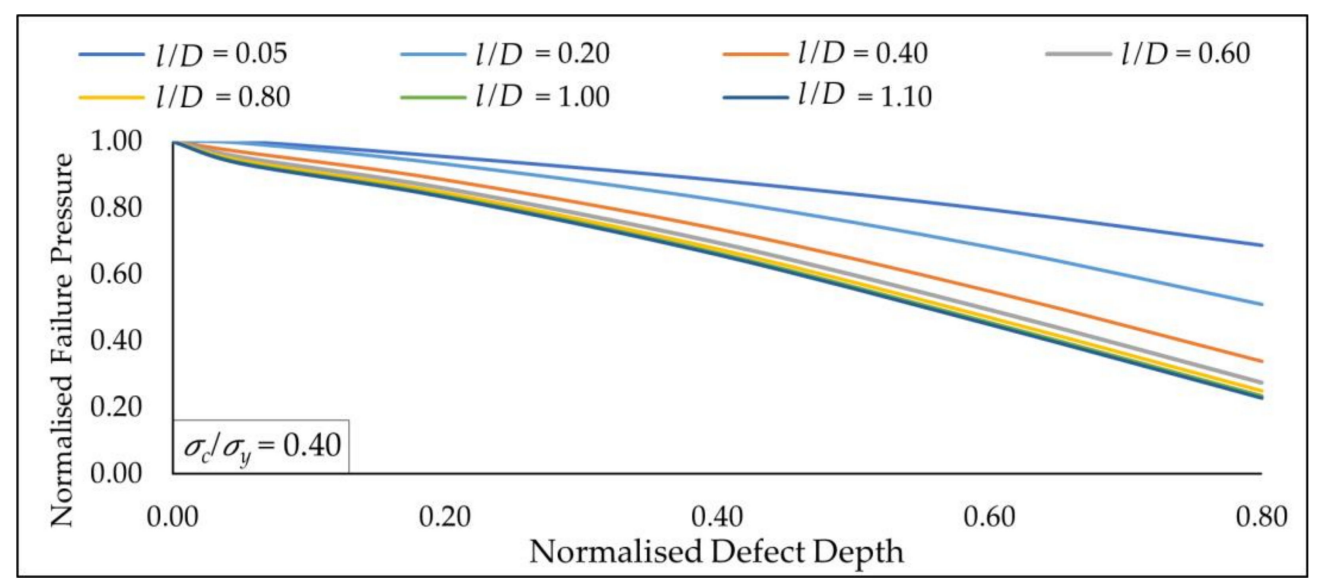

Figure 20. Normalized failure pressure predictions of the new assessment method against various normalized defect depth for multiple normalised defect lengths at a constant normalized axial compressive stress of 0.40 .

\subsubsection{Effects of Axial Compressive Stress on the Failure Pressure of a Pipe}

Based on Figure 21, at a constant normalised defect length of 0.6, it was observed that the normalised failure pressure decreases insignificantly for normalised axial compressive stress values of 0.0 to 0.4 . Under these conditions, the maximum normalised failure pressure decrease was observed to be only $8.46 \%$ based on normalised defect depth values of 0.05 to 0.80 . For normalised axial compressive stress values of 0.40 to 0.60 , the normalised failure pressure drops significantly by a maximum of $24.48 \%$. This indicates that when a normalised axial compressive stress value of 0.4 to 0.8 is imposed on a pipe, it causes a significant decrease in the normalised failure pressure of the pipe. This pattern was also observed for normalised defect length values of $0.2,0.4$, and 0.8 .

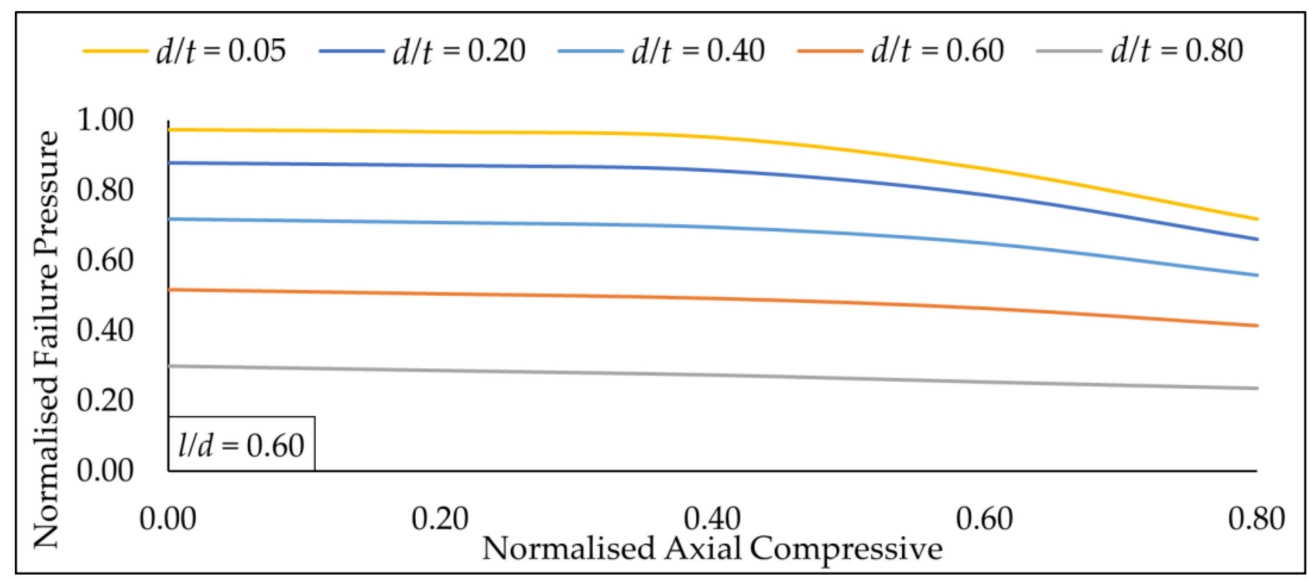

Figure 21. Normalized failure pressure predictions of the new assessment method against various normalized axial compressive stress for multiple normalised defect depths at a constant normalized defect length of 0.60 . 


\subsection{Recommendations for Future Studies}

The current equation is limited only to the prescribed range and material. Future studies should consider using a greater number of ANN training datasets that consist of different types of material and varying parameters of corrosion defects to increase the accuracy of the ANN model, as well as the equation. To create a robust artificial neural network, more training data covering greater parameter variations should be considered during the generation of the ANN data. By doing so, a general equation that is applicable to more material types and corrosion defect geometries can be achieved without compromising on the accuracy of the results.

\section{Conclusions}

Despite being the most comprehensive corrosion assessment method, the DNV code results in an inaccurate failure pressure prediction due to the assumptions, simplifications, and the lack of method validation for high toughness pipes subjected to internal pressure and axial compressive stress. FEM has proven to produce accurate failure pressure predictions with a very strong correlation with actual full-scale burst tests. Using this method together with ANN has shown promising results in the development of an empirical solution for the failure pressure prediction of pipes with a single corrosion defect subjected to internal pressure and axial compressive stress.

FEA was used to generate training data using API 5L X80 pipe grade. The weights and biases of the ANN model were then used to develop an empirical equation for the failure pressure prediction of a high toughness pipe with single corrosion defect subjected to internal pressure and axial compressive stress as a function of normalised defect length, depth, and axial compressive stress. The new method predicted failure pressures for API 5L X80 and X100 pipes with an error percentage of less than $10.00 \%$ for normalised defect depths of 0.1 to 0.8 , normalised defect lengths of 0.1 to 1.1 , normalised axial compressive stress from 0.2 to 0.8 and pipe grades ranging from API 5L X80 to X100. Hence, this method is suitable for the failure pressure prediction of high toughness pipes ranging from API 5L X80 to X100 grades with normalised defect length, normalised defect depth, and normalised axial compressive stress that are within the mentioned ranges.

Author Contributions: Conceptualization, S.K. and M.O.; methodology, S.D.V.K.; software, S.K.; validation, S.D.V.K. and S.K.; formal analysis, S.D.V.K. and S.K.; investigation, S.D.V.K.; resources, S.K.; data curation, S.D.V.K. and S.K.; writing-original draft preparation, S.D.V.K.; writing-review and editing, S.K. and M.O.; visualization, S.K. and M.O.; supervision, S.K.; project administration, S.K.; funding acquisition, S.K. All authors have read and agreed to the published version of the manuscript.

Funding: This research and the APC was funded by Yayasan University Teknology PETRONAS, Malaysia, grant number 015LC0-110.

Institutional Review Board Statement: Not applicable.

Informed Consent Statement: Not applicable.

Conflicts of Interest: The authors declare no conflict of interest.

\section{Abbreviations}

$\begin{array}{ll}\text { Nomenclature } & \begin{array}{l}\text { Description } \\ \text { ANSYS }\end{array} \\ & \begin{array}{l}\text { ANSYS 16.1 Structural Product of Mechanical ANSYS Parametric Design } \\ \text { Language (APDL) }\end{array} \\ \text { DNV } & \text { DNV-RP-F101 corrosion assessment method } \\ \text { DOF } & \text { Degrees of freedom } \\ \text { FE } & \text { Finite element } \\ \text { FEA } & \text { Finite element analysis } \\ \text { FEM } & \text { Finite element method }\end{array}$




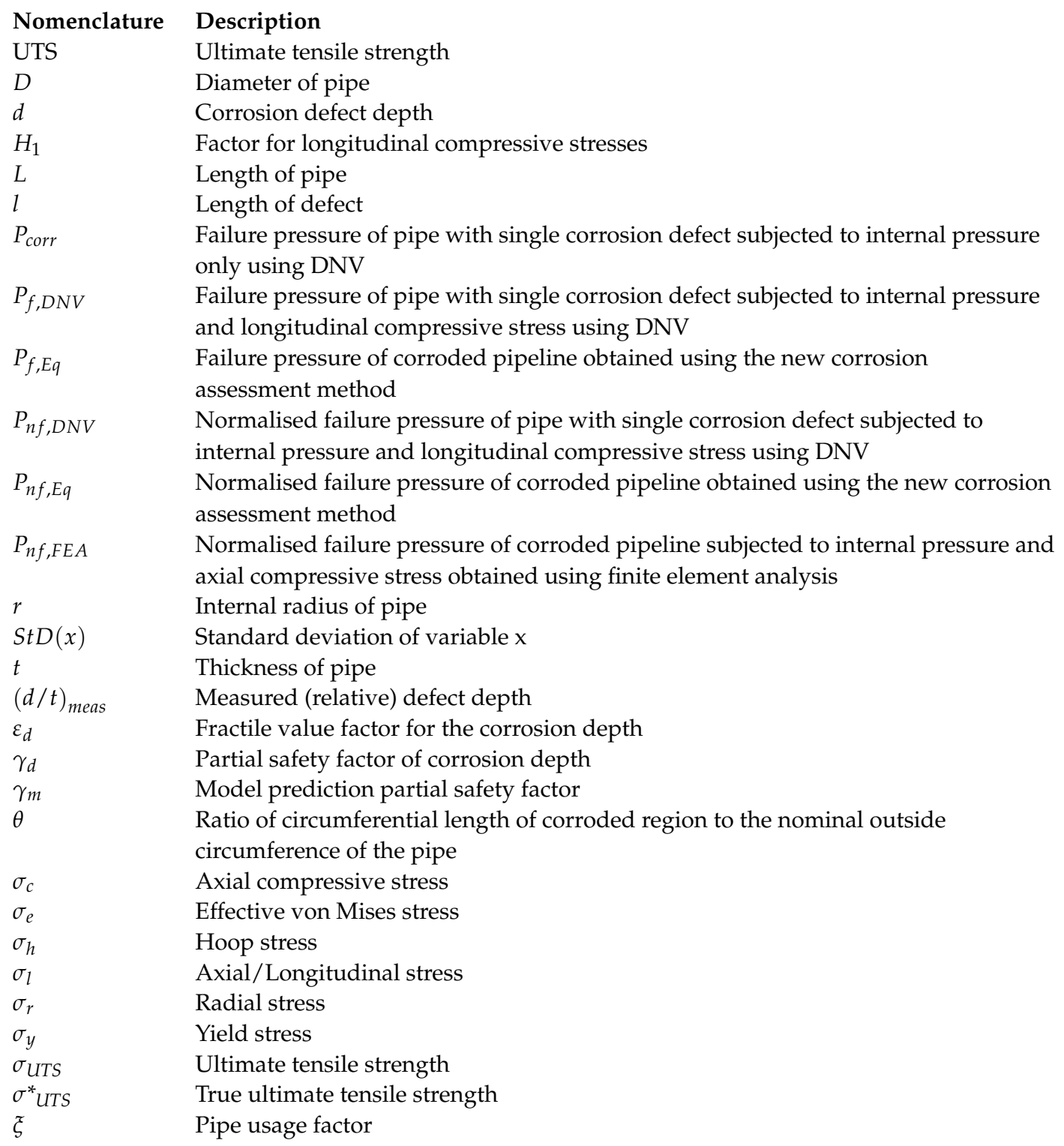

\section{References}

1. Ren, L.; Jiang, T.; Jia, Z.-G.; Li, D.-S.; Yuan, C.-L.; Li, H.-N. Pipeline corrosion and leakage monitoring based on the distributed optical fiber sensing technology. Measurement 2018, 122, 57-65. [CrossRef]

2. Arumugam, T.; Karuppanan, S.; Ovinis, M. Residual strength analysis of pipeline with circumferential groove corrosion subjected to internal pressure. Mater. Today Proc. 2020, 29, 88-93. [CrossRef]

3. Cosham, A.; Palmer, A.; Hopkins, P. The Assessment of Corrosion in Pipeline-Guidance in The Pipeline Defect Assessment Manual (PDAM). In Proceedings of the Pipeline Pigging and Integrity Management Conference, Amsterdam, The Netherlands, 17-18 May 2004.

4. Belachew, C.T.; Ismail, M.C.; Karuppanan, S. Burst Strength Analysis of Corroded Pipelines by Finite Element Method. J. Appl. Sci. 2011, 11, 1845-1850. [CrossRef]

5. Fekete, G.; Varga, L. The effect of the width to length ratios of corrosion defects on the burst pressures of transmission pipelines. Eng. Fail. Anal. 2012, 21, 21-30. [CrossRef]

6. American Society of Mechanical Engineers. Manual for Determining the Remaining Strength of Corroded Pipelines: Supplement to ASME B31 Code for Pressure Piping; American Society of Mechanical Engineers: New York, NY, USA, 2015.

7. DNV. Recommended Practice DNV-RP-F101; DNV: Oslo, Norway, 2017.

8. Kiefner, J.F.; Vieth, P.H. A Modified Criterion for Evaluating the Remaining Strength of Corroded Pipe; No. PR-3-805; U.S. Department of Energy Office of Scientific and Technical Information: Oak Ridge, OH, USA, 1989.

9. Amaya-Gómez, R.; Sanchez-Silva, M.; Bastidas-Arteaga, E.; Schoefs, F.; Munoz, F. Reliability assessments of corroded pipelines based on internal pressure-A review. Eng. Fail. Anal. 2019, 98, 190-214. [CrossRef] 
10. Gao, J.; Yang, P.; Li, X.; Zhou, J.; Liu, J. Analytical prediction of failure pressure for pipeline with long corrosion defect. Ocean Eng. 2019, 191, 106497. [CrossRef]

11. Arumugam, T.; Karuppanan, S.; Ovinis, M. Finite element analyses of corroded pipeline with single defect subjected to internal pressure and axial compressive stress. Mar. Struct. 2020, 72, 102746. [CrossRef]

12. Chiodo, M.S.G.; Ruggieri, C. Failure assessments of corroded pipelines with axial defects using stress-based criteria: Numerical studies and verification analyses. Int. J. Press. Vessel. Pip. 2009, 86, 164-176. [CrossRef]

13. Ahammed, M.; Melchers, R.E. Probabilistic analysis of underground pipelines subject to combined stresses and corrosion. Eng. Struct. 1997, 19, 988-994. [CrossRef]

14. Chauhan, V.; Swankie, T.D.; Espiner, R.; Wood, I. Developments in Methods for Assessing the Remaining Strength of Corroded Pipelines. In Proceedings of the NACE Corrosion 2009 Conference Expo, Atlanta, GA, USA, 22-26 March 2009; pp. 1-29.

15. Mokhtari, M.; Melchers, R.E. A new approach to assess the remaining strength of corroded steel pipes. Eng. Fail. Anal. 2018, 93, 144-156. [CrossRef]

16. Dewanbabee, H.; Das, S. Structural Behavior of Corroded Steel Pipes Subject to Axial Compression and Internal Pressure: Experimental Study. J. Struct. Eng. 2013, 139, 57-65. [CrossRef]

17. Li, X.; Chen, Y.; Zhou, J. Plastic Interaction Relations for Corroded Steel Pipes under Combined Loadings. In Proceedings of the 12th Biennial International Conference on Engineering, Construction, and Operations in Challenging Environments; and Fourth NASA/ARO/ASCE Workshop on Granular Materials in Lunar and Martian Exploration, Honolulu, HI, USA, 14-17 March 2010; pp. 3328-3344.

18. Seyfipour, I.; Bahaari, M.R. Analytical study of subsea pipeline behaviour subjected to axial load in free-span location. J. Mar. Eng. Technol. 2018, 4177, 1-8. [CrossRef]

19. De Andrade, E.Q.; Benjamin, A.C.; Machado, P.R., Jr.; Pereira, L.C.; Jacob, B.P.; Carneiro, E.G.; Guerreiro, J.N.C.; Silva, R.C.C.; Noronha, D.B., Jr. Finite element modeling of the failure behavior of pipelines containing interacting corrosion defects. In Proceedings of the International Conference on Offshore Mechanics and Arctic Engineering-OMAE, Hamburg, Germany, 4-9 June 2006; Volume 2006. [CrossRef]

20. Song, H.; Zhang, Y.; Yin, X.; Wang, L.; Wang, W.; Xia, F. How to improve the prediction accuracy of the ANN model to underground water content effectively. In Proceedings of the 2011 International Symposium on Water Resource and Environmental Protection, Xi'an, China, 20-22 May 2011; Volume 1, pp. 350-353. [CrossRef]

21. Haque, M.E.; Sudhakar, K.V. Prediction of corrosion-fatigue behavior of DP steel through artificial neural network. Int. J. Fatigue 2001, 23, 1-4. [CrossRef]

22. Xu, W.-Z.; Li, C.B.; Choung, J.; Lee, J.-M. Corroded pipeline failure analysis using artificial neural network scheme. Adv. Eng. Softw. 2017, 112, 255-266. [CrossRef]

23. Chen, Y.; Zhang, H.; Zhang, J.; Li, X.; Zhou, J. Failure analysis of high strength pipeline with single and multiple corrosions. Mater. Des. 2015, 67, 552-557. [CrossRef]

24. Cosham, A.; Hopkins, P.; Macdonald, K. Best practice for the assessment of defects in pipelines-Corrosion. Eng. Fail. Anal. 2007, 14, 1245-1265. [CrossRef]

25. Cronin, D.S.; Pick, R.J. Prediction of the failure pressure for complex corrosion defects. Int. J. Press. Vessel. Pip. 2002, 79, $279-287$. [CrossRef]

26. Wang, Y.-L.; Li, C.-M.; Chang, R.-R.; Huang, H.-R. State evaluation of a corroded pipeline. J. Mar. Eng. Technol. 2016, 15, 88-96. [CrossRef]

27. ANSYS. ANSYS Theory Reference; ANSYS Inc.: Canonsburg, PA, USA, 2019.

28. Wiesner, C.; Maddox, S.; Xu, W.; Webster, G.; Burdekin, F.; Andrews, R.; Harrison, J. Engineering critical analyses to BS 7910-The UK guide on methods for assessing the acceptability of flaws in metallic structures. Int. J. Press. Vessel. Pip. 2000, 77, 883-893. [CrossRef]

29. Terán, G. Failure Pressure Estimations for Pipes with Combined Corrosion Defects on the External Surface: A Comparative Study. Int. J. Electrochem. Sci. 2017, 12, 10152-10176. [CrossRef]

30. Bjørnøy, O.H.; Sigurdsson, G.; Cramer, E. Residual Strength of Corroded Pipelines, DNV Test Results. In Proceedings of the Tenth International Offshore and Polar Engineering Conference, Seattle, WA, USA, 28 May-2 June 2000.

31. Ma, B.; Shuai, J.; Liu, D.; Xu, K. Assessment on failure pressure of high strength pipeline with corrosion defects. Eng. Fail. Anal. 2013, 32, 209-219. [CrossRef]

32. Benjamin, A.C.; Freire, J.L.F.; Vieira, R.D.; Diniz, J.L.; de Andrade, E.Q. Burst Tests on Pipeline Containing Inter-acting Corrosion Defects. In Proceedings of the 24th International Conference on Offshore Mechanics and Arctic Engineering (OMAE 2005), Halkidiki, Greece, 12-17 June 2005; pp. 1-15. 